\title{
The Ubiquitin-Proteasome System and the Autophagic-Lysosomal System in Alzheimer Disease
}

\author{
Yasuo Ihara ${ }^{1}$, Maho Morishima-Kawashima ${ }^{2}$, and Ralph Nixon ${ }^{3,4}$ \\ ${ }^{1}$ Department of Neuropathology, Faculty of Life and Medical Science, Doshisha University, \\ Kyoto 619-0225, Japan \\ ${ }^{2}$ Department of Molecular Neuropathology, Graduate School of Pharmaceutical Sciences, Hokkaido \\ University, Sapporo 060-0812, Japan \\ ${ }^{3}$ Center for Dementia Research, Nathan Kline Institute, Orangeburg, New York 10962 \\ ${ }^{4}$ Departments of Psychiatry and Cell Biology, New York University Langone Medical Center, New York, \\ New York 10016 \\ Correspondence: yihara@mail.doshisha.ac.jp; nixon@nki.rfmh.org
}

\begin{abstract}
As neurons age, their survival depends on eliminating a growing burden of damaged, potentially toxic proteins and organelles-a capability that declines owing to aging and disease factors. Here, we review the two proteolytic systems principally responsible for protein quality control in neurons and their important contributions to Alzheimer disease pathogenesis. In the first section, the discovery of paired helical filament ubiquitination is described as a backdrop for discussing the importance of the ubiquitin-proteasome system in Alzheimer disease. In the second section, we review the prominent involvement of the lysosomal system beginning with pathological endosomal-lysosomal activation and signaling at the very earliest stages of Alzheimer disease followed by the progressive failure of autophagy. These abnormalities, which result in part from Alzheimer-related genes acting directly on these lysosomal pathways, contribute to the development of each of the Alzheimer neuropathological hallmarks and represent a promising therapeutic target.
\end{abstract}

$\mathrm{C}$ ellular aging, the sine qua non for Alzheimer disease development, is associated with cumulative oxidative damage to proteins and membranes, translational errors leading to the synthesis of defective proteins, and various genetic and environmental insults to organelles and proteins (Terman 2001; Roy et al. 2002; Sohal et al. 2002; Troen 2003; Levine et al. 2004). In some aging-related neurodegenerative diseases, mutations of the pathogenic gene(s) may also cause anomalous conformations of the encoded protein or its metabolites, leading to increased proteolytic resistance and accumulation of these potentially toxic proteins (Soto 2003). A neuron's ability to function in the face of these mounting aging- and diseaserelated insults is determined in significant part by the efficiency with which it can eliminate

Editors: Dennis J. Selkoe, Eckhard Mandelkow, and David M. Holtzman

Additional Perspectives on The Biology of Alzheimer Disease available at www.perspectivesinmedicine.org

Copyright (C) 2012 Cold Spring Harbor Laboratory Press; all rights reserved; doi: 10.1101/cshperspect.a006361

Cite this article as Cold Spring Harb Perspect Med 2012;2:a006361 
Y. Ihara et al.

this burden of damaged cellular constituents. An array of proteases regulates cell function, but two proteolytic systems are mainly responsible for the turnover of proteins and organelles - the proteasome and lysosomal systems (Grune et al. 2001; Berke et al. 2003; Goldberg 2003; Levine et al. 2004). The proteasome selectively degrades normal proteins (mainly those with short half-lives) and abnormal proteins, which are earmarked for elimination by a process involving their conjugation to ubiquitin (Ub; Goldberg 2003). The lysosomal system, and specifically the autophagic pathway, is the principal mechanism for degrading proteins with long half-lives and is the only system in cells for degrading organelles and large protein aggregates or inclusions. A second route to lysosomes, the endocytic pathway, delivers extracellular material and plasma membrane constituents to lysosomes under the direction of specific targeting signals (Nixon 2004).

Not surprisingly, protein quality control and proteostasis - the appropriate balance of protein synthesis, folding, and turnover in the cell-involve interdependent regulation of these two proteolytic systems. This interdependence is best exemplified by the regulatory influences of the protein ubiquitin. It has recently become appreciated that ubiquitination of proteins by covalent modification tags them for elimination not only through the proteasome (the ubiquitin-proteasome system or UPS) but also through the lysosomal system. Endocytosed receptors are targeted for lysosomal degradation, in part, by ubiquination in late endosomes/multivesicular bodies (MVBs). Recently, protein aggregates and certain organelles have been shown to be tagged with ubiquination for selective removal by autophagy (Narendra et al. 2009; Dikic et al. 2010; Youle et al. 2011), a degradative process previously believed to be only nonselective. In selective autophagy, an adaptor molecule with a ubiquitin-binding domain engages the ubiquitinated structure and couples it to the pre-autophagosomal isolation membrane for subsequent sequestration. The exact types of ubiquitin motifs recognized by the UPS and autophagy may differ and the degree to which ubiquitination drives autophagic protein turnover relative to that by proteasomes is still unclear. Nevertheless, the role of ubiquitin as a tag for targeting substrates for elimination is more universal than earlier imagined, implying that changes in ubiquitin balance may be one way that disease-related perturbations of one proteolytic system are likely to influence the other.

Interdependence of the proteasome and lysosomal system is also suggested by observations that, when proteasome activity is inhibited, proteins accumulate that become substrates for autophagy (Fortun et al. 2003). Inhibiting autophagy by genetically deleting components of the sequestration machinery causes ubiquitinated protein aggregates to appear in neurons, reflecting additional negative effects on the UPS (Korolchuk et al. 2009a,b). Besides ubiquitin, proteins identified to play regulatory roles in the UPS and autophagy are being increasingly identified (Zhao et al. 2007). For example, p62, an adaptor protein for autophagy, also influences proteasomal degradation, whereas VCP/p97 acting through p62 and ubiquitin regulates both the proteasome-dependent endoplasmic reticulumassociated degradation (ERAD) pathway and aspects of autophagosome maturation (Tresse et al. 2010). The E3 ligase Parkin, a protein implicated in Parkinson's disease, creates an autophagy signal on mitochondria and also tags proteins elsewhere for proteasomal degradation (Yoshii et al. 2011). Interestingly, proteasomal subunits may be degraded by lysosomes (Cuervo et al. 1995), hinting at an additional level of cross talk between these proteolytic systems.

Proteolysis has been an active area of $\mathrm{Alz}$ heimer disease research over the past two decades mainly in relation to the processing of specific proteins, like the $\beta$-amyloid precursor protein. A broader appreciation is emerging, however, of the roles of proteolytic systems in other crucial aspects of Alzheimer disease (AD) pathogenesis related to protein clearance, neural plasticity, and neurodegenerative mechanisms. In this article, we focus on the involvement of the UPS and the lysosomal system (endosomal-lysosomal pathway and autophagy) in $\mathrm{AD}$, 
their contributions to disease development and progression, and the possibilities for targeting these systems in the design of innovative therapies for $\mathrm{AD}$.

\section{PART I: THE UBIQUITIN-PROTEASOME SYSTEM IN AD}

\section{Discovery of Ubiquitin in Paired Helical Filaments: A Personal Retrospective by Yasuo Ihara}

Polyclonal antibodies to the classical paired helical filaments (PHFs) found in the neurofibrillary tangles and dystrophic neurites of $\mathrm{AD}$ were first raised in about 1982, allowing exploration of the component(s) of PHFs using immunochemical approaches (Ihara et al. 1983). This strategy was useful because PHFs were resistant to conventional protease digestion, and it was difficult to obtain reproducible and distinct limited-digest protein fragments of PHFs for sequencing. Sodium dodecyl sulfate (SDS)-insoluble material was extracted from typical AD brains, and PHFs were partially purified from the SDS-insoluble material by differential centrifugation and sucrose density gradient centrifugation (Ihara et al. 1983). The PHFs obtained by these procedures were not yet sufficiently pure, as shown later by sequencing of fragments of PHF proteins (Kondo et al. 1988). The polyclonal PHF antisera that were initially raised also reacted with lipofuscin-like granules and other SDS-insoluble materials in the PHF-rich immunogen. A major frustration with the antisera was that, although they intensely stained neurofibrillary tangles (NFTs), dystrophic neurites, and neuropil threads in $\mathrm{AD}$ brain sections, they did not label a distinct band(s) on immunoblots of $\mathrm{AD}$ brain homogenates, instead giving peculiar smears running from very high to low molecular mass (Ihara et al. 1983). These immunoreactive smears were highly characteristic of AD brain homogenates and never seen in control brain homogenates. Thus, the indirect immunochemical approach to identify the PHF component proteins seemed unsuccessful at first. However, it succeeded a few years later when fetal or neonatal brain homogenates were probed with antiPHF antisera: A somewhat diffuse band around $50 \mathrm{kDa}$ was intensely labeled in immunoblots of fetal brain homogenates. This protein reactive with the initial anti-PHF sera was soon identified as tau, a microtubule-associated protein (MAP), based on its molecular weight, isoform change during development, microtubule-binding activity, and heat stability (Kosik et al. 1986; Nukina and Ihara 1986; see also Brion et al. 1985; Grundke-Iqbal et al. 1986; Wood et al. 1986; discovery of tau in PHF is reviewed in Mandelkow and Mandelkow 2011).

In contrast to our initial PHF antisera, we assumed that a monoclonal antibody that recognizes a highly defined epitope on PHF would not give rise to the smearing pattern on immunoblots that greatly puzzled us. In 1985, we became aware of a hybrid system (Pike et al. 1982) for raising monoclonal antibodies to glycolipids. Lewis rats responded well to immunizations with partially purified PHF preparations, yielding high titers of antisera to PHFs. These rats provided splenocytes for fusion with mouse myeloma cells. We (Hiroshi Mori and Yasuo Ihara) employed a two-step screening procedure to identify monoclonals in the resultant hybridoma supernatants: first by enzymelinked immunosorbent assay (ELISA) using plates coated with partially purified PHFs, and second by immunostaining of NFTs that were prepared from $\mathrm{AD}$ brains under nondenaturing conditions. Only two confirmed and stable cell lines emerged, the antibodies from which had very similar specificities on the blots: Besides the characteristic "PHF smear," they also labeled a very small protein of $\sim 8 \mathrm{kDa}$. Hiroshi Mori named these monoclonal antibodies DF (Dementia Filament) 1 and 2, of which the latter (DF2) was used for subsequent characterization (Mori et al. 1987).

In contrast to our PHF antisera, DF2 produced immunoreactive smears even in control brain homogenates (presumably representing Ub-conjugated proteins). In addition, DF2 gave a distinct band at $8 \mathrm{kDa}$ on blots of aged human brain homogenates, whereas the PHF 
Y. Ihara et al.

antisera had not given distinct bands. We were puzzled as to why the two antibodies labeled different bands, but hypothesized that they recognized different components of PHFs. Optical diffraction analyses carried out by Wischik et al. (1985) had suggested that the core of the PHF may be composed of a subunit around $\sim 100 \mathrm{kDa}$. We reasoned that one protein might make up the core framework of PHFs, whereas another might occur on a peripheral portion.

In $\mathrm{AD}$ cortical sections, we observed that NFTs and dystrophic neurites (Fig. 1) and, unexpectedly, granulovacuolar changes (Fig. 1, inset) were intensely immunolabeled by the DF2 monoclonal. When mild fixation conditions were used, innumerable neuropil threads were also detected. (One peculiar characteristic was an apparent "background" staining of AD brain sections, whereas widely used Ub polyclonal antibodies [Haas and Bright 1985] gave almost no background staining. This discrepancy was resolved in 1996: DF2 is specific for the conjugated form of $\mathrm{Ub}$, whereas the $\mathrm{Ub}$ polyclonal antibodies are specific for free $\mathrm{Ub}$ [Morimoto et al. 1996].)

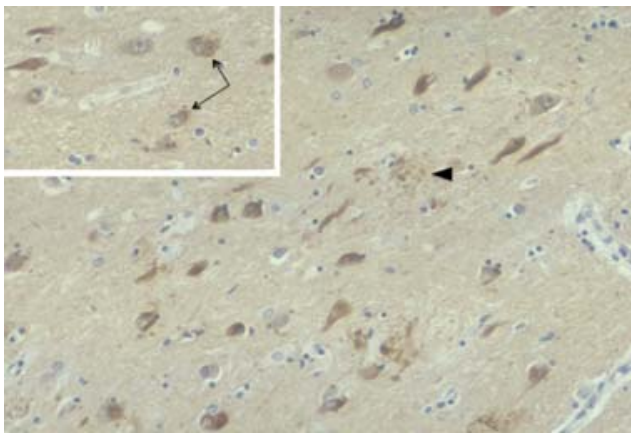

Figure 1. DF2 immunostaining of a tissue section from Alzheimer disease (AD) hippocampus. Neurofibrillary tangles and dystrophic neurites (arrowhead) are intensely labeled, whereas the neuropil (background) is uniformly stained, simulating nonspecific background staining. However, this was found to be true staining of ubiquitin-conjugated proteins in the neuropil (Morimoto et al. 1996). (Inset) Some neurons in CA1 undergo granulovacuolar changes (arrows) and are also intensely stained with DF2.
What was the small protein at $8 \mathrm{kDa}$ that was strongly labeled by DF2? Purifying the protein was not difficult with high-performance liquid chromatography (HPLC), which was beginning to be used for protein fractionation. The sequence of the DF2-reactive protein up to approximately 30 residues exactly corresponded to that of ubiquitin (Mori et al. 1987). This was probably the first description of Ub protein modification in the field of neuropathology. Two seminal papers describing the significance of protein ubiquitination had recently been published by the Varshavsky laboratory (Ciechanover et al. 1984; Finley et al. 1984). Despite reading these papers, we could not understand why Ub is present on PHFs. Our understanding was that $\mathrm{Ub}$ is a tag for protein degradation: A Ub-tagged protein should be recognized and degraded by the proteasome, an unusually large cytoplasmic protease. However, Ub was found to have other functional roles; for example, a proportion of histone (H)2B is ubiquitinated in a way that has a role in the transcription.

Ubiquitin appeared to represent a novel constituent of PHFs; DF2 strongly stained SDS-stripped NFTs, suggesting that Ub was an integral component. Nevertheless, we felt that the immunochemical identification of the component was not sufficient to fully confirm the presence of the molecule on PHFs. At the time, there was some confusion about the PHF protein constituents. Using well-characterized antibodies to various MAPs as well as PHF polyclonal antibodies, tau had recently been established as a major component of PHFs (see above and Mandelkow and Mandelkow 2011). However, monoclonal antibodies to neurofilament (NF) proteins also strongly immunolabeled PHF (Anderton et al. 1982), and these were widely applied to AD brain sections. This confusion about PHF components was clarified when Nobuyuki Nukina and coworkers found significant cross-reactivities of certain NF monoclonal antibodies with phosphorylated epitopes of tau (Nukina et al. 1987). In light of such observations, it became essential to show unambiguously that Ub was a component of PHF. In 1987, we finally obtained 
definitive evidence using protein chemical techniques that $\mathrm{Ub}$ was integral to the PHF (Mori et al. 1987).

\section{Ubiquitinated Tau in PHFs: K48-Linked Mono- and Polyubiquitin Modification}

In the mid 1980s, the distinction between monoand polyubiquitination was not yet clear, and the role of the multiubiquitin chain as a strong degradative signal was just emerging. A fraction of $\mathrm{H} 2 \mathrm{~B}$ was shown to be monoubiquitinated, and lymphocyte homing receptor was similarly found to be ubiqutinated, but the significance of monoubiquitination was entirely unclear. In our research on Ub in PHFs, we were unable to identify the Ub-conjugated protein by direct sequencing. It was most likely to be tau, but we had no definitive evidence. In the period 19891992, the Ihara laboratory was mostly involved in determining the phosphorylation sites on tau proteins in PHFs. We became aware that ion spray mass spectroscopy (MS) was an excellent method for determining phosphorylation sites on PHF-tau (Hasegawa et al. 1992). This provided an opportunity to reanalyze purified PHFs from AD cortex and identify the Ub-targeted protein.

We had previously raised antibodies to the carboxy-terminal region (Gly-76) of Ub, which was predicted to be conjugated with $\varepsilon$-amino groups of lysines of other proteins targeted for proteasomal degradation. However, despite repeated trials using these antibodies, we were unable to identify a particular HPLC peak containing the Ub carboxyl terminus. In our hands, Ub reactivity was detected exclusively in the insoluble $\mathrm{AD}$ brain fractions displaying so-called "PHF smears" on immunoblots. However, Ub itself was not responsible for this smear pattern, because we also observed Ubnegative/tau-positive smears, in addition to Ub-positive/tau-positive smears (MorishimaKawashima et al. 1993). The guanidine $\mathrm{HCl}-$ solubilized, Ub- and tau-reactive material purified from AD cortex by HPLC was subjected to peptide mapping using Achromobacter lyticus protease I (AP1), which is highly specific for Lys-X bonds. This yielded peaks corresponding to API-generated fragments of Ub (Fig. 2), in addition to carboxy-terminal fragments of tau, whereas virtually no fragments derived from the amino-terminal portion of tau were recovered. As expected, fragments U1-U7 (see Fig. 2) were found in our digests, but U8 (the carboxy-terminal portion of $\mathrm{Ub}$ ) was undetectable at the expected position of the nonconjugated U8. Instead, we observed several unusual HPLC peaks that neither corresponded to U1-U8 nor occurred in the digests of Ub-negative/tau-positive smears. By protein sequencing and MS, we identified four Ub-conjugated sites on tau (Fig. 3) and further identified K48-linked Ub chains (Morishima-Kawashima et al. 1993). Crude estimates suggested that most of the products were derived from monoubiquitination and only a minority from polyubiquitination.

These Ub- and tau-reactive smears were recovered exclusively from the buffer-insoluble fraction of $\mathrm{AD}$ cortex, suggesting that ubiquitination might occur after tau deposits into

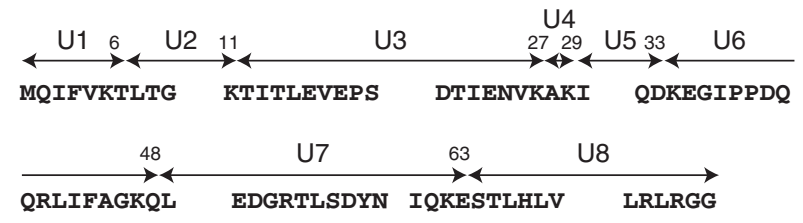

Figure 2. Schematic illustration of 76-residue ubiquitin. Ubiquitin has seven lysine residues and Achromobacter lyticus protease 1 (AP1) cleaves ubiquitin into eight fragments, U1-U8. G76 is conjugated with $\varepsilon$-amino groups of lysine in the target protein. K48-linked ubiquitin chain is a strong degradation signal. Besides this, K6-, 11-, 27-, 29-, and 63-linked multiubiquitin chains are found in the cell (Xu and Peng 2006). It is likely that each type of chain has a distinct role in the cellular metabolism. 
Y. Ihara et al.

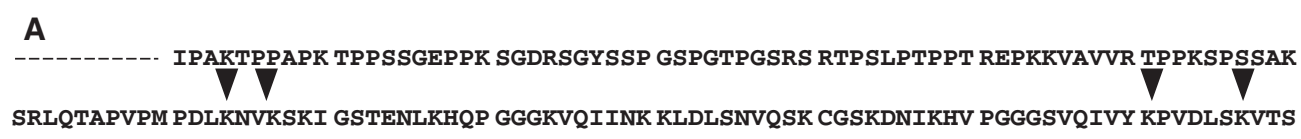

KCGSLGNIHH KPGGGQVEVK SEKLDFKDRV QSKIGSLDNI THVPGGGNKK IETHKLTFRE NAKAKTDHGA EIVYKSPVVS

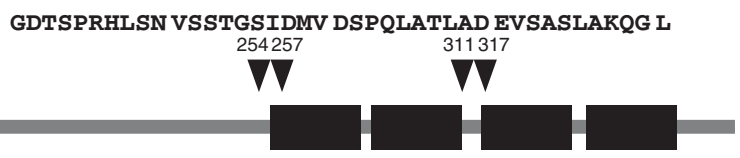

B

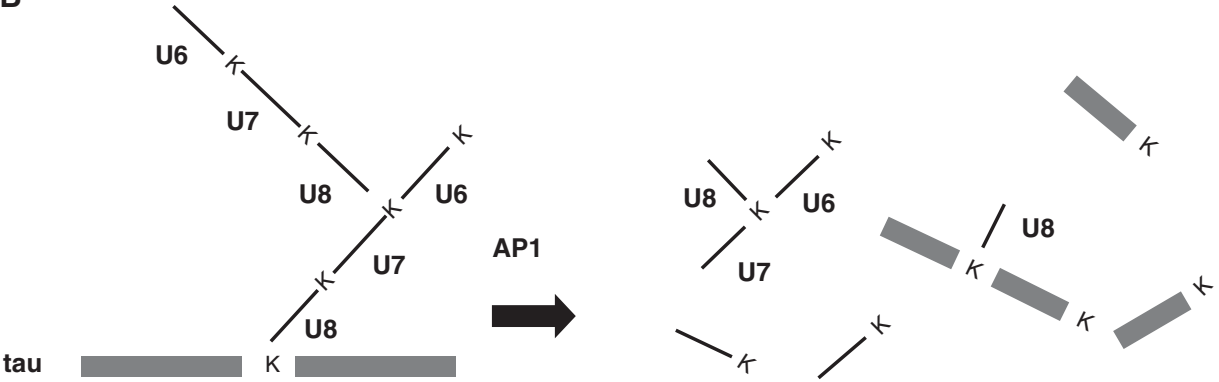

Figure 3. Ubiquitination sites on amino terminally processed tau. As shown in $A$, four ubiquitin conjugation sites were identified. These are located close to and in the microtubule-binding domain, K254, 257, 311, and 317 according to the numbering of the 441 amino acid human tau isoform. A size exclusion-purified paired helical filament PHF smear was further purified by reverse-phase HPLC, giving three broad (overlapped) peaks that existed only in smear fractions from $\mathrm{AD}$ brain. The last-eluting fraction contained a ubiquitin (Ub)-positive, tau-positive smear, which was subjected to AP1 digestion and reverse HPLC fractionation, followed by amino acid sequencing and mass spectrometric analysis. Several late-eluting peaks were found to contain branched fragments, mostly consisting of tau fragments and U8; a minority of U8 conjugated with Lys-48 of U6-U7, derived from the polyubiquitin chain (Morishima-Kawashima et al. 1993). Dysfunction of autophagic and endocytic pathways to lysosomes driven by relevant genes and other risk factors in Alzheimer disease (expressed on the left side of the diagram) causes or promotes pathophysiology critical to the development and progression of the disease (outlined on the right side of the diagram). See the text for further details.

aggregates. At that time, a simple model showed that cells conjugated Ub to abnormal proteins that were to be selectively degraded by the proteasome. If this was correct, minute amounts of abnormal PHF proteins tagged by Ub and targeted for the proteasome might be observed in the buffer-soluble fraction of cytoplasm, but we were unable to confirm this. However, recent work by Cripps et al. (2006) successfully used MC1 (a monoclonal specific for an abnormal PHF-like conformation of tau) to affinity purify soluble full-length tau from PHF-rich extracts of AD cortex and subject it to liquid chromatography-tandem MS (LC-MS/MS) analysis. The presence of K6, $\mathrm{K} 11$, and K48- linked polyubiquitinations-in addition to monoubiquitination - was observed. Among these polyubiquitination sites, the K48linked site was predominant. It is thus possible that a portion of MC1-reactive PHF-tau is in the soluble fraction and exists as free molecules in the cytoplasm, but this has not yet been confirmed.

Interestingly, immunocytochemical staining suggests that Ub exists in the mid-portion of neuropil threads (the largest source of PHF in the $\mathrm{AD}$ brain), whereas both ends of the threads are reactive for only tau, not Ub (Iwatsubo et al. 1992). This finding suggests that neuropil threads may extend at both ends: Tau may aggregate and deposit first, followed by its ubiquitination. 


\section{Ubiquitination of Other Neuropathological Inclusions}

Following the discoveries about $\mathrm{Ub}$ and PHFs reviewed above, a variety of types of $\mathrm{Ub}-$ protein conjugates were detected in other neurodegenerative diseases. Although such findings were initially based solely on immunocytochemical evidence, we and others postulated that ubiquitination may be widely involved in the degradation of cytoplasmic proteins accumulating during aging and in a number of neurodegenerative diseases. Therefore, ubiquitinated inclusions may represent a failure of degradation by the $\mathrm{Ub}$-proteasome system of neurons or glia. Early on, it was thought that Ub was associated with intermediate (10-nm) filaments in cells, because many inclusions seemed to consist of "altered" intermediate filaments (Lowe et al. 1988).

With the knowledge that DF2 recognizes $\mathrm{Ub}$, we investigated whether DF2 stains other types of known intracellular inclusions. In the cortex, DF2 revealed fine dot-like stainings that had not been described before, and larger dot-like stainings were seen in the white matter, possibly derived from multivesicular and lysosome-related bodies. In addition, DF2 intensely labeled the classical granulovacuolar changes in the hippocampus in $\mathrm{AD}$ and other neurodegenerative disorders (Fig. 1, inset). We soon found that DF2 strongly stained cortical and brain stem Lewy bodies in brain sections from "diffuse Lewy body disease" (Kuzuhara et al. 1988), as originally described by Kenji Kosaka (1978), who proposed that some elderly subjects dying with dementia had many cortical Lewy bodies. In this dementia, Lewy bodies are abundant in cortical neurons, especially in the cingulate gyrus, in addition to their presence in the substantia nigra and locus ceruleus, their prototypical loci in Parkinson's disease. The eosinophilic round bodies with clear margins in brainstem neurons and the somewhat indistinct, smaller round bodies in cortical neurons are sometimes difficult to recognize with conventional hematoxylin-eosin stains, but anti-Ub antibodies such as DF2 labeled them well. Furthermore, DF2 revealed a possible evolution of Lewy bodies: Diffuse cytoplasmic accumulation of Ub-positive material might be followed by its gradual coalescence into an amorphous perinuclear inclusion (Kuzuhara et al. 1988). DF2 and other Ub antibodies also labeled elongated neurites (now known as Lewy neurites) in and near the sites of Lewy bodies. Because Lewy bodies did not stain for tau, the target protein of ubiquitination had to be distinct. In 1997, $\alpha$-synuclein was shown to be the principal component of Lewy bodies (Spillantini et al. 1997). The accumulated $\alpha$-synuclein was then shown to be ubiquitinated (Hasegawa et al. 2002).

The DF2 immunoreactivity of Lewy bodies led us to search for similar DF2-positive inclusions, and we found that Lewy-like bodies in motor neurons in amyotrophic lateral sclerosis (ALS; Murayama et al. 1990a) and Pick bodies in Pick's disease (Murayama et al. 1990b) were strongly reactive; the latter stained also for tau, whereas the former stained neither for tau nor $\alpha$-synuclein. In this regard, the entity of frontotemporal lobar degeneration (FTLD) with Ub-positive/tau-negative inclusions was described later, and TDP43 was identified as the ubiquitinated protein in both this disorder and ALS (Neuman et al. 2006). It is noteworthy that the specific protein targets of ubiqutination that accumulate in insoluble deposits in distinct disorders have apparent major roles in the respective neurodegenerative processes: In $\mathrm{AD}$, tau is ubiquitinated, in Parkinson's disease and dementia with Lewy bodies, it is $\alpha$-synuclein, and in ALS and FTLD-U, it is TDP-43.

\section{Significance of Ubiquitinated Neurofibrillary Tangles}

The discovery of tau ubiqutination in PHFs suggested that living (but presumably injured) neurons may mount an attempt to remove the abnormal inclusions (NFTs) by Ub tagging, although this apparently fails to efficiently remove the tangles. The UPS was believed to be involved principally in the turnover of short-lived proteins (cytosolic, nuclear, and endoplasmic reticulum [ER]), and especially 
Y. Ihara et al.

tightly regulated transcription factors; for this process, the proteolytic system requires adenosine triphosphate (ATP). There was initially a view that long-lived proteins, including tau, may be degraded principally by lysosomes, the other major protein degradation machinery of the cell.

Ubiquitination occurs in three steps. The first step is activation of the carboxyl terminus of Ub by an E1 protein (i.e., a Ub-activating enzyme), which consumes ATP. Second, there is conjugation of the ATP-activated $\mathrm{Ub}$ to an E2 protein (i.e., a Ub-conjugating enzyme). Third, there is ligation of Ub with an $\varepsilon$-amino group of lysine in the target protein by an E3 ligase. E3 ligase binds both the target protein and the E2-Ub complex; thousands of substrate-specific E3s ensure selective protein tagging and degradation. An E4 enzyme catalyzes the polyubiquitination of the target substrate that is bound to the E2-E3 complexes. Proteins tagged with chains of four or more K48-linked multiubiquitins provide the strongest signal for degradation by the $26 \mathrm{~S}$ proteasome, because a chain of at least four Ub moieties is required for substrate recognition by the $26 \mathrm{~S}$ proteasome complex. Ubiquitinated target proteins bind to the 19S cap (RP), which has a Ub binding site and ATPase activity, and this leads to cleavage of Ub moieties from the target by deubiquitinating enzymes, unfolds the polypeptides and sends them to the narrow channel of the $20 \mathrm{~S}$ core particle. The narrow canal of $20 \mathrm{~S}$ proteasome $(\sim 700 \mathrm{kDa})$ consists of heptameric stacks of four rings, with the inner two being composed of $\beta$ subunits and the outer two of $\alpha$ subunits (Gallastegui and Groll 2010). Thus, the general structure of the $20 \mathrm{~S}$ core particle is $\alpha_{1-7} \beta_{1-7} \beta_{1-7} \alpha_{1-7}$ (Fig. 4). These subunits have activities as trypsin-like, chymotrypsinlike, and peptidyl-glutaminyl hydrolyzing activities. The catalytic portions face the interior surface; during its passage, the target protein is processed to short peptides, mostly between six and 10 amino acids. Deubiquitinating activity attached to the $19 \mathrm{~S}$ cap is essential for complete degradation; if this is blocked, degradation is inhibited, and ubiquitinated substrates accumulate in the cytoplasm.

The $26 \mathrm{~S}$ proteasome is primarily a cytosolic enzyme, but it is also found in ER membranes and localized to nuclei. The former activity is known as ER-associated degradation. The latter (nuclear) activity is thought to be involved in

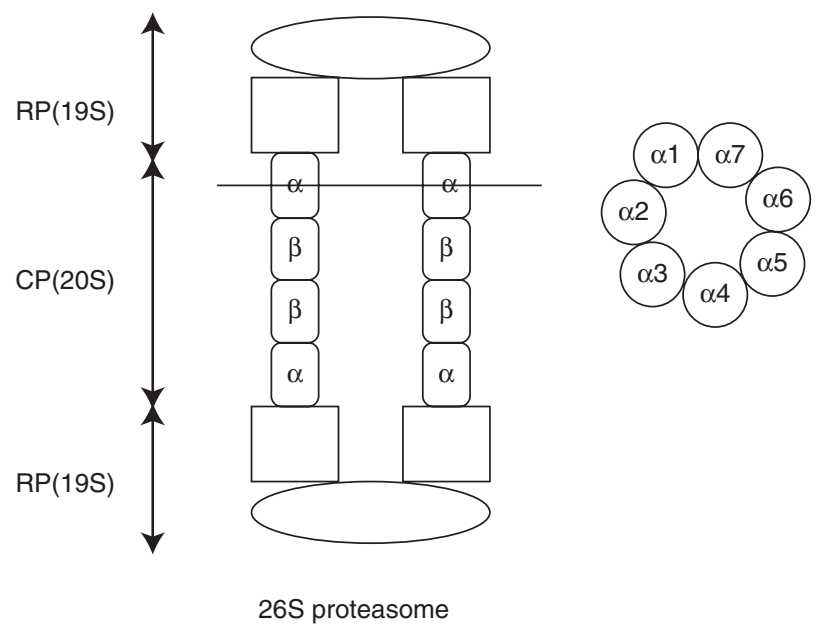

Figure 4. Schematic illustration of $26 \mathrm{~S}$ proteasome. It consists of $19 \mathrm{~S}$ regulatory particle (RP) and 20S core particle (CP). The narrow canal of CP consists of heptameric stacks of four rings, with the inner two being composed of $\beta$ subunits and the outer two of $\alpha$ subunits. The image on the right shows a cross section at an indicated line (left). These subunits have trypsin-like, chymotrypsin-like, and peptidyl glutaminyl hydrolyzing activities. (Modified from Gallastegui and Groll 2010.) 
the development of the ubiquitinated nuclear inclusions found in Huntington's disease and some types of spinocerebellar ataxia.

The question arises whether a fundamental impairment of proteasome function is involved in the formation of intracellular aggregates, in particular the NFT of AD. AD is the most common of numerous age-associated brain diseases, and the activity of brain proteasomes appears to decline with age (Keller et al. 2002). PHF have been associated with inhibition of the activity of the proteasome in a brain region-specific manner (Keller et al. 2000). That is, in areas where NFTs formed abundantly, including hippocampus and parahippocampal gyrus and superior and middle temporal gyri, proteasome activity (as assessed by chymortrypsinlike and postglutamyl peptidases) appeared to be most affected, whereas occipital gyri and cerebellum, which often have few or no NFTs, were least affected (Keller et al. 2000). Despite the decreased proteasomal enzymatic activity observed in AD brains, the levels of the $\alpha$ and $\beta$ subunits were not decreased. This suggests that posttranslational modifications could cause the decreases in the activities of proteasome. Another study of AD brain tissues showed that hyperphosphorylated tau was bound to the proteasome, presumably to the $19 \mathrm{~S}$ cap portion, and the more tau that was bound, the more that proteasomes appeared to be inhibited (Keck et al. 2003). In vitro experiments further showed that aggregated (recombinant) tau-but not nonaggregated (monomeric) tau-can inhibit the proteasome activity. The hyperphosphorylation of tau may not be related to suppression of proteasomes. Based on these various findings, it has been speculated that small aggregates of PHFs may bind to the cap portion of the $26 \mathrm{~S}$ proteasome and inhibit its activity. This hypothesis is consistent with related observations made in other cell model systems (Bence et al. 2001). Taken together, the available evidence suggests that PHF-bearing neurons have defective activity of some of their proteasomes, which may contribute to the neurodegeneration. On the other hand, it seems unlikely that the decreasing activity of the proteasome leads to NFT formation. Aggregate formation itself may be a protective event in $\mathrm{AD}$ neurons and help extend their life spans, as compared with neurons not bearing NFTs (Gomez-Isla et al. 1997).

The currently prevailing view of the temporal involvement of Ub in PHF evolution is that the aggregation of hyperphosphorylated tau is followed by ubiquitination. This is consistent with previous immunocytochemical observations (Bancher et al. 1991) and also with confocal microscopy reconstructions, suggesting that, in the neuropil threads of AD cortex, both growing ends of the threads contain fulllength tau, whereas $\mathrm{Ub}$ is present at the mid portion, where the amino-terminal region of tau may have been processed (Iwatsubo et al. 1992). Similarly, in our biochemical studies, ubiquitinated tau was undetectable in the soluble fraction of cortex (but see Cripps et al. 2006), and only a portion of amino-terminally processed tau in the insoluble fraction was ubiquitinated (Morishima-Kawashima et al. 1993). The question remains why only a minority of the ubiquitin tagged to the processed tau in PHF is in the form of polyubiquitin chains, and what the significance is of the monoubiquitination that appears to represent the majority of ubiquitin found in PHFs (Morishima-Kawashima et al. 1993).

\section{The Ubiquitin-Proteasome System in AD}

Since ubiquitin immunoreactivity has been documented in a range of inclusion bodies, a role of the UPS in the pathogenesis of a number of neurodegenerative diseases, especially in $\mathrm{AD}$, has been considered. Several molecules that are relevant to the UPS have been shown to be associated with AD. Let us first discuss $\mathrm{UBB}^{+1}$, a mutant form of ubiquitin extending 19 amino acids at its carboxyl terminus which is generated owing to dinucleotide deletions of the ubiquitin mRNA through "molecular misreading" (van Leeuwen et al. 1998). $\mathrm{UBB}^{+1}$ protein accumulates in brains affected by $\mathrm{AD}$ and other diseases such as Pick's disease and Huntington's disease (Fischer et al. 2003). Because of the absence of the carboxy-terminal Gly-76, $\mathrm{UBB}^{+1}$ cannot ubiquitinate other proteins, but it is itself ubiquitinated efficiently. The 
Y. Ihara et al.

resulting polyubiquitinated $\mathrm{UBB}^{+1}$ cannot be degraded by proteasomes and impairs the UPS (Lam et al. 2000), which may induce neurotoxicity. Indeed, transgenic mice expressing $\mathrm{UBB}^{+1}$ have an impaired UPS and show contextual memory deficits in both water maze and fear conditioning paradigms, without specific neuropathological findings (Fischer et al. 2009). Further, $\mathrm{UBB}^{+1}$ can enhance the susceptibility of yeast to the toxicity of protein aggregates (Tank et al. 2009).

Ubiquitin carboxy-terminal hydrolase L1 (UCH-L1), which was originally identified as a deubiqutinating enzyme, has multiple functions, including as a ubiquitin ligase and a stabilizer of monoubiquitinated proteins (Setsuie and Wada 2007). Although UCH-L1 is genetically associated with Parkinson's disease (i.e., it is the PARK5 gene; Belin and Westerlund 2008), it has also been implicated in the pathogenesis of $\mathrm{AD}$. A proteomic analysis has shown down-regulation and oxidative modification of $\mathrm{UCH}-\mathrm{L} 1$ in the AD brain, and the levels of soluble UCH-L1 were inversely proportional to the number of NFTs (Choi et al. 2004). Moreover, administration of UCH-L1 can reverse the amyloid $\beta$-protein-induced synaptic dysfunction and memory loss in transgenic mice overexpressing APP and PS1 (Gong et al. 2006).

Next, ubiquilin-1 has been reported to be genetically linked to AD. Ubiquilin-1 interacts with both proteasomes and ubiquitinated proteins and regulates the proteasomal degradation of various proteins, including presenilin 1 (Haapasalo et al. 2010). An intronic polymorphism involving alternative splicing of exon 8 in the ubiquilin 1 gene ( $U B Q L N 1$ ), which is genetically located near a well-established linkage peak for $\mathrm{AD}$ on chromosome 9q22, has been associated with increased risk for lateonset AD (Bertram et al. 2005). However, this finding has not been replicated by others (Smemo et al. 2006).

The earliest symptoms of AD are believed to be due to synaptic dysfunction, and in this context, numerous studies have established a significant role of the UPS in the regulation of synaptic plasticity. Although ubiquitin tagging was originally identified as a signal for protein destruction by the proteasome system, ubiquitination is now known to be a posttranslational modification in which ubiquitins can serve as signals for protein localization and sorting in various physiological phenomena such as signal transduction, the cell cycle, transcription, DNA repair, and endocytosis. In particular, the critical role of the UPS in synaptic plasticity, learning and memory formation needs to be emphasized (Bingol and Sheng 2011). The role of the UPS in synaptic plasticity was first highlighted in Aplysia. During the induction of long-term facilitation in the snail, the regulatory subunit of cAMP-dependent protein kinase (PKA) is ubiquitinated and degraded by the proteasome, generating persistently activated PKA (Hegde et al. 1993). Activated PKA induces transcription of ApUCH (UCH-L1 in mammals), a deubiquitinating enzyzme, which has been found to be critical for the induction of long-term facilitation (Hegde et al. 1997). It is now known that the UPS also regulates turnover of neurotransmitter receptors, protein kinases, synaptic proteins, transcription factors, and other molecules critical for proper synaptic plasticity, thus controlling synaptic strength and connections during brain development in mammals (Bingol and Sheng 2011). The UPS is also critically involved in learning and memory. Bilateral injection of lactacystin, a specific proteasome inhibitor, into the CA1 region of the rat hippocampus blocks long-term memory formation (Lopez-Salon et al. 2001). This and numerous related findings suggest that degradation of certain critical proteins by the UPS is required during long-term memory formation. One of these proteins is arc, a negative regulator of synaptic strength that promotes the internalization of AMPA receptors and is degraded via the E3 ligase, UBE3A (Greer et al. 2010).

Synaptic loss has long been documented in AD brain (Gonatas et al. 1967) and, as expected, is strongly correlated with the degree of cognitive impairment (Terry et al. 1991). In transgenic mouse models of $\mathrm{AD}$, synaptic deficits have been detected prior to the formation of amyloid plaques (Hsia et al. 1999). Among the various molecular species of $A \beta$ present in the brain, soluble oligomeric forms of $A \beta$ are 
arguably the most plausible candidates to impair synaptic function (reviewed in Walsh and Selkoe 2004). Soluble A $\beta$ oligomers inhibit hippocampal long-term potentiation and alter memory and learning performance. They also facilitate long-term depression by, among other effects, disrupting synaptic glutamate uptake (Li et al. 2009). Recently, it has been shown that soluble $\mathrm{A} \beta$ oligomers isolated from $\mathrm{AD}$ cortex can induce tau hyperphosphorylation at $\mathrm{AD}$-relevant epitopes and subsequent neuritic degeneration (Jin et al. 2011). Beyond an age-related reduction (Keller et al. 2002), proteasome activities decrease in $\mathrm{AD}$ in a brain region-specific manner, particularly in hippocampus, parahippocampal gyrus, superior and middle temporal gyri, and the inferior parietal lobule (Keller et al. 2000), areas that are especially critical for long-term memory formation. Moreover, soluble A $\beta$ oligomers themselves can inhibit proteasomal activity (Tseng et al. 2008). Thus, it is possible that additive effects of $A \beta$ oligomers and reduced proteasome activities in $\mathrm{AD}$ may accelerate synaptic dysfunction.

It is still unsettled how the degradation of tau is regulated under physiological conditions. It has been reported that tau is degraded by several major cellular degradation systems, including calpain, caspases, lysosomes, and proteasomes. As regards the proteasome, both the ATP-dependent 26S proteasome and the ATP-independent 20S proteasome have been reported to degrade normal, soluble tau (Cardozo et al. 2002; Zhang et al. 2005). However, administration of inhibitors of the proteasome has provided conflicting results: Treatment with lactacystin either did or did not suppress the degradation of tau (David et al. 2002; Brown et al. 2005a). On the other hand, it has been reported that the E3 ligase CHIP (carboxyl terminus of the Hsc70-interacting protein) binds to tau and is involved in the degradation of abnormal forms of tau, including insoluble tau and hyperphosphorylated tau, coordinately with Hsp70 (Petrucelli et al. 2004; Dickey et al. 2006). As described above, it has also been found that the $20 \mathrm{~S}$ proteasome interacts with tau aggregates (Keck et al. 2003). Collectively, such findings suggest that the UPS may be implicated more in the degradation of abnormal forms of tau than of normal, soluble tau.

As in the case of tau, an impairment of proteasome activity by protein aggregates is observed for other proteins, such as polyglutamine-expanded proteins, the prion protein, and $A \beta$ (Bence et al. 2001). Notably, immunotherapy against $A \beta$ in the $3 x T g-A D$ mice, which reduces $A \beta$ oligomers, reverses the proteasome deficits of these transgenic mice (Tseng et al. 2008). Thus, the accumulation of tau and of $A \beta$, forming the two major protein lesions of $\mathrm{AD}$, impairs proteasome activity in vivo.

Despite the substantial indirect evidence just reviewed that associates UPS dysfunction with key features of $\mathrm{AD}$, it remains unclear whether aberration in the UPS plays a causative or only a secondary role. Besides its key role in the UPS, ubiquitin is now known to function as a signal tag in the lysosome-autophagy system (see below). Indeed, many recent studies suggest the involvement of autophagy in the pathogenesis of AD. For example, immunocytochemistry showing the presence of K63linked polyubiquitin in a fraction of the NFTs in $\mathrm{AD}$ cortex (Paine et al. 2009) suggests an active involvement of autophagy in the mechanism of AD.

\section{PART II: THE AUTOPHAGY AND THE ENDOSOMAL-LYSOSOMAL SYSTEM IN AD}

\section{The Lysosomal Network}

The endocytic and autophagic pathways share in common the role of delivering unneeded cellular materials to lysosomes for degradation and recycling to provide energy and new synthesis. Vesicular compartments in these pathways actively cross-talk and have common points of regulation (Simonsen et al. 2009; Settembre et al. 2011). Under pathological conditions, a deficit in one pathway often impedes functioning of the other. Therefore, it is reasonable to view these two pathways, which intersect at the lysosome, as comprising a lysosomal network (Fig. 5).

Although key to the survival of all cells, endocytosis supports unique neuronal functions, including aspects of synaptic transmission and 
Y. Ihara et al.

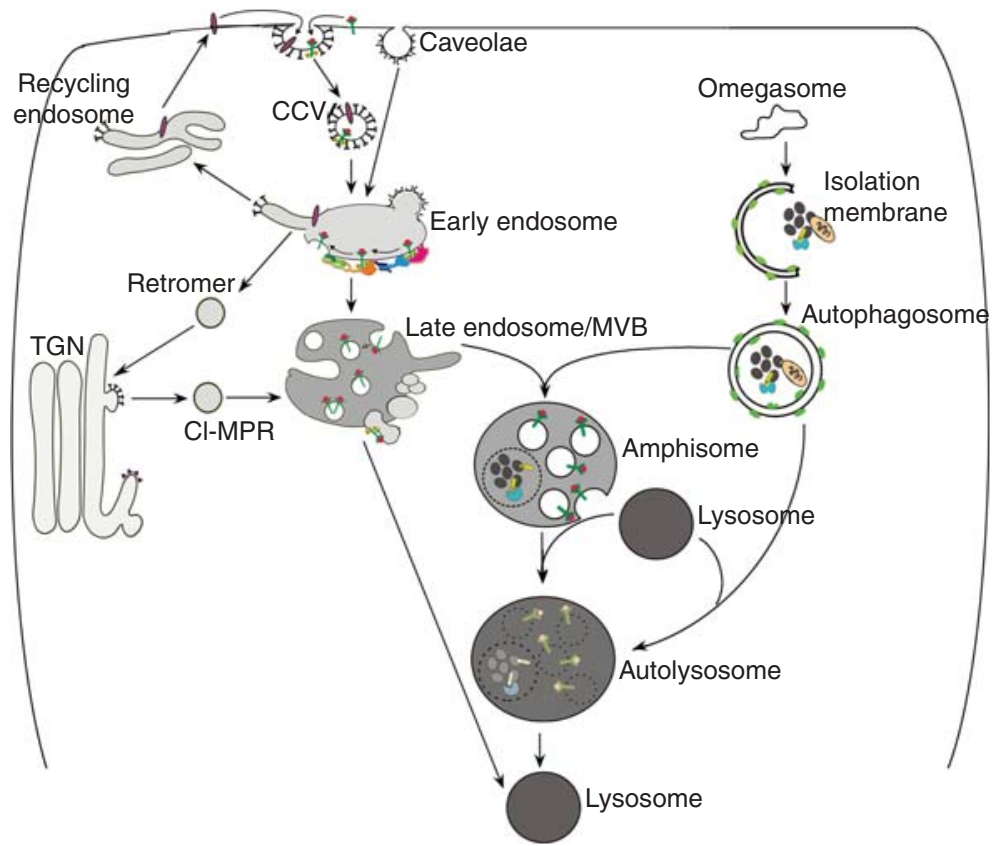

Figure 5. Schematic illustrating the endocytic and the autophagic pathways to the lysosome. See the text for details.

plasticity underlying memory and learning. Also, extracellular signals (e.g., growth factors) activate surface receptor complexes that, upon internalization, undergo retrograde axonal transport within "signaling endosomes" to promote neuronal survival and differentiation (Delcroix et al. 2003). That these vital processes are initiated in synaptic terminals at great distances from the perikaryon renders neurons particularly vulnerable to impairments of endocytic function and vesicular transport.

During the initiation of endocytosis, the invagination of plasma membranes into vesicles is mediated most often by the clathrin/adaptor protein complex, but also via caveolae or bulk macropinocytosis (Lim et al. 2011). Cargoes are delivered to early sorting endosomes through fusion mediated by the small GTPase Rab5 and additional Rab5 effector proteins (Fig. 5). Many cell surface proteins and lipids are returned to the plasma membrane via recycling endosomes, whereas other components are delivered to the Golgi by the retromer complex (Kelly et al. 2011). Still other cargoes reach late endosomes when Rab7 and its effectors replace Rab5 and initiate further endosomal maturation (Poteryaev et al. 2010). An MVB is then created by inward budding of the surface membrane (Piper et al. 2001), thereby sorting cargoes into intraluminal vesicles. Ubiquitin, the crucial signal for efficient sorting of proteins into the MVB (Babst et al. 1997), initiates this process, which is mediated by a group of ESCRT complexes (endosomal sorting complex required for transport; Hurley 2010). Acid hydrolases, including cathepsins, are delivered from the trans-Golgi network (TGN) to MVBs/ late endosomes by either of two mannose-6phosphate receptors: cation-dependent $46 \mathrm{kDa}$ MPR (CD-MPR) and cation-independent $215 \mathrm{kDa}$ MPR (CI-MPR; Mullins et al. 2001). Proteolysis begins in late endosomes/MVBs but accelerates upon fusion with lysosomes, where cathepsins are activated by the highly acidic ( $\mathrm{pH} 4.5-5.5)$ intraluminal environment. The acidic $\mathrm{pH}$ is achieved mainly through the ATP-dependent proton pump, vacuolar ATPase (Nishi et al. 2002), but is also modulated by a 
group of chloride, sodium, calcium, and potassium transporters (Pillay et al. 2002).

Autophagy is the cell's principal degradative pathway for eliminating unwanted organelles and long-lived proteins and for clearing damaged, aggregated, or obsolete proteins (Wong et al. 2010). Autophagy refers to at least three processes by which intracellular constituents reach the lumen of MVBs or lysosomes for degradation: chaperone-mediated autophagy (CMA), microautophagy, and macroautophagy (Cuervo 2004; Levine et al. 2011). In CMA, cytosolic proteins containing a KFERQ motif (including proteins pathogenic in some neurodegenerative diseases) are selectively targeted by certain chaperones to the lysosomal lumen for degradation (Arias et al. 2011). Microautophagy involves the nonselective entry of small quantities of cytoplasm into lysosomes or late endosomes/MVBs when the limiting membranes of these compartments invaginate and pinch off small vesicles for digestion within the lumen (Sahu et al. 2011). Finally, macroautophagy mediates bulk or targeted degradation of cytoplasmic constituents. During macroautophagy, an elongated "isolation" membrane created from a preautophagosomal structure sequesters a region of cytoplasm to form a double-membrane-limited autophagosome (Fig. 5). Two ubiquitin-like protein conjugation pathways are known to coordinate this process (Ohsumi 2001). Sequestered material within autophagosomes is digested when lysosomes or late endosomes fuse with the outer membrane of the autophagosome (Gordon et al. 1988). Amphisomes formed by the fusion of autophagosomes with early endosomes or MVBs/late endosomes are especially important in neurons, where a considerable proportion of endocytosed cargo is directed to the autophagic pathway prior to being degraded by lysosomes (Larsen et al. 2002). This is especially true in axons (Lee et al. 2011). Induction of autophagy is generally controlled by the mTOR kinase (mammalian Target of Rapamycin), which is regulated by growth factors (especially insulin) and nutrient levels. Autophagy is constitutively active in neurons and is nonselective under nutrient deprivation conditions but may be selective when damage uncovers a molecular target on an organelle such as a mitochondrion (Youle et al. 2011), which initiates signaling and a ubiquitin-ligase-mediated chain of events that triggers selective sequestration of the organelle (Dikic et al. 2010; Weidberg et al. 2011).

\section{Molecular Pathology of the Lysosomal Network}

A continuum of pathological changes of the lysosomal network unfolds in neurons as Alzheimer disease progresses, including dysregulation of endocytosis, increased lysosome biogenesis and, later, progressive failure of lysosomal clearance mechanisms (Fig. 6; Nixon et al. 2006). These changes can be driven by known $\mathrm{AD}$ genetic and environmental risk factors, as discussed later. Endosome anomalies are the earliest specific pathology reported in $\mathrm{AD}$ brain tissue. Neuronal endosome enlargement, which is not characteristically observed in other major neurodegenerative diseases, develops in pyramidal neurons of the neocortex at a stage when plaques and tangles are restricted only to the hippocampus (Braak stage 2) and not in brains of similarly aged individuals free of AD-like hippocampal pathology (Cataldo et al. 1997, 2000). Similar endosomal anomalies develop gradually in Down syndrome brain, beginning decades before the appearance of classical AD pathology (Cataldo et al. 2000). Genes related to endocytosis, such as Rab5, Rab7, and Rab4, are among the earliest groups to show up-regulated transcription in AD (Ginsberg et al. 2010), and their corresponding proteins are abnormally recruited to endosomes, where they promote fusion and abnormal enlargement of early and late endosomes (Cataldo et al. 1997, 2008). This pattern is not seen in normal aging brain and is specific for $\mathrm{AD}$ among aging-related neurodegenerative diseases that have been studied (Cataldo et al. 2000).

As neuronal endosomes begin to enlarge, lysosomal biogenesis rises, as evidenced by lysosome proliferation and increased expression of acid hydrolases and other lysosome-related proteins (Nixon et al. 2006). Lysosome proliferation is followed by progressive enlargement 
Y. Ihara et al.

A

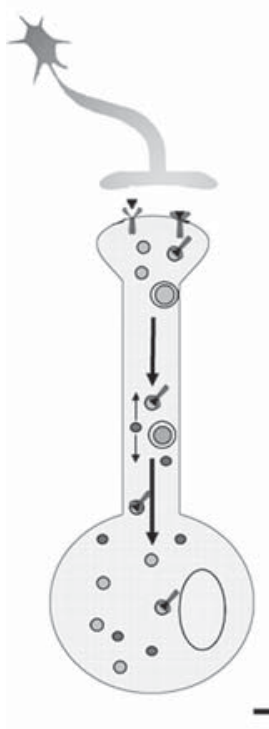

D

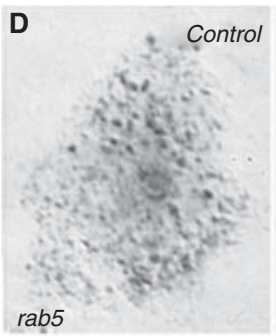

rab5

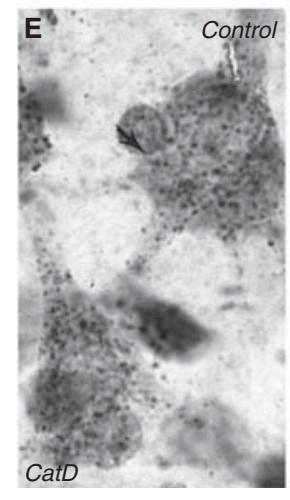

B

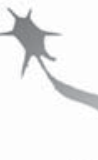


Ubiquitin-Proteasome and Autophagy in AD

and distortion of these compartments. Cathepsin-positive vacuoles massively accumulate within swellings of dystrophic neurites throughout the neuropil and in senile plaques as they develop (Cataldo et al. 1990, 1991). Ultrastructural investigations of AD brain biopsies have revealed that the most prevalent organelles by far within dystrophic swellings are autophagic vacuoles (AVs), representing all stages of the macroautophagic process (Nixon et al. 2005), including autophagosomes. This implies that the progression of autophagy is delayed or impaired, because AVs are relatively rare in normal brain. $\mathrm{AV}$ accumulations are not specific to the degenerative phenomena of $\mathrm{AD}$; however, in $\mathrm{AD}$ brain, the extensive numbers of dystrophic neurites (Masliah et al. 1993; Schmidt et al. 1994), their characteristic marked distension, and the fact that they are predominantly filled with $\mathrm{AVs}$ distinguish the pattern and magnitude of this pathology from that of other aging-related neurodegenerative diseases (Benzing et al. 1993). In non-AD neurodegenerative disorders, many types of vesicles and cytoskeletal elements are relatively abundant, suggesting general axonal transport failure distinct from the selective transport deficits seen in $\mathrm{AD}$ (Lee et al. 2011a,b).

The profuse and selective accumulation of $\mathrm{AV}$ s in neurons in $\mathrm{AD}$ reflects a defect in the clearance of $\mathrm{AVs}$ by lysosomes rather than an abnormally elevated induction of autophagy. The accumulating AVs are mainly electrondense autolysosomes, indicating that autophagosome-lysosome fusion is relatively competent. Similar autophagy pathology is observed when lysosomal proteolysis is inhibited (Ivy et al. 1984; Koike et al. 2005; Yang et al. 2008). That presenilin 1 mutations, which are a cause of early-onset familial $\mathrm{AD}$, impede lysosome proteolysis and accelerate neuritic dystrophy also supports a primary role for failure of proteolytic clearance (Lee et al. 2010). Increased autophagy induction in $\mathrm{AD}$ could, however, compound the defect in $\mathrm{AV}$ clearance in $\mathrm{AD}$. Transcription of many lysosomal genes and factors promoting autophagy is up-regulated, whereas negative regulators of autophagy are down-regulated (Lipinski et al. 2010), although not all studies support enhanced autophagy induction in AD (Pickford et al. 2008; Nixon et al. 2011).

\section{AD Genetics Implicates the Lysosomal Network in Pathogenesis}

Genetic factors that represent the strongest support for the amyloid/A $\beta$ cascade hypothesis also act directly through $\mathrm{A} \beta$-independent mechanisms to dysregulate the lysosomal network and contribute not only to $A \beta$ accumulation but also to other critical aspects of $\mathrm{AD}$ pathogenesis (Fig. 7). Beyond its role as a component of $\gamma$-secretase, Presenilin 1 (PS1) is required for lysosome acidification, which is needed to activate cathepsins and other hydrolases that carry out digestion during autophagy (Lee et al. 2010). In the absence of PS1, the V0a1 subunit of v-ATPase is not $\mathrm{N}$-glycosylated in the ER and is degraded before sufficient amounts can be delivered to autolysosomes/lysosomes to support lysosomal acidification. This function of PS1 is independent of the aspartyl protease activity of the molecule because proteolytically inactive PS1 mutated at one or both catalytic aspartates is able to restore normal lysosome acidification in PS1-deleted cells (Lee et al. 2010). Importantly, PS1 mutations also inhibit this process in fibroblasts from patients with familial AD (Lee et al. 2010), providing a basis for defective autophagy and the potentiation of autophagic-lysosomal and amyloid pathology and accelerated neuronal cell death observed in PS-FAD (Cataldo et al. 2004).

An additional copy of the App gene (genomic duplication) is sufficient to cause another form of early-onset FAD (Rovelet-Lecrux et al. 2006; Sleegers et al. 2006). App promoter polymorphisms that increase APP expression are also associated with early-onset AD (Athan et al. 2002). These findings support a longstanding hypothesis that the App gene on the trisomic copy of human chromosome 21 (HSA21) in Down syndrome (DS) is principally responsible for the invariant early development of $\mathrm{AD}$ in DS individuals (Margallo-Lana et al. 2004). In DS, the extra copy of App causes endocytic up-regulation and endosome pathology similar 
Y. Ihara et al.

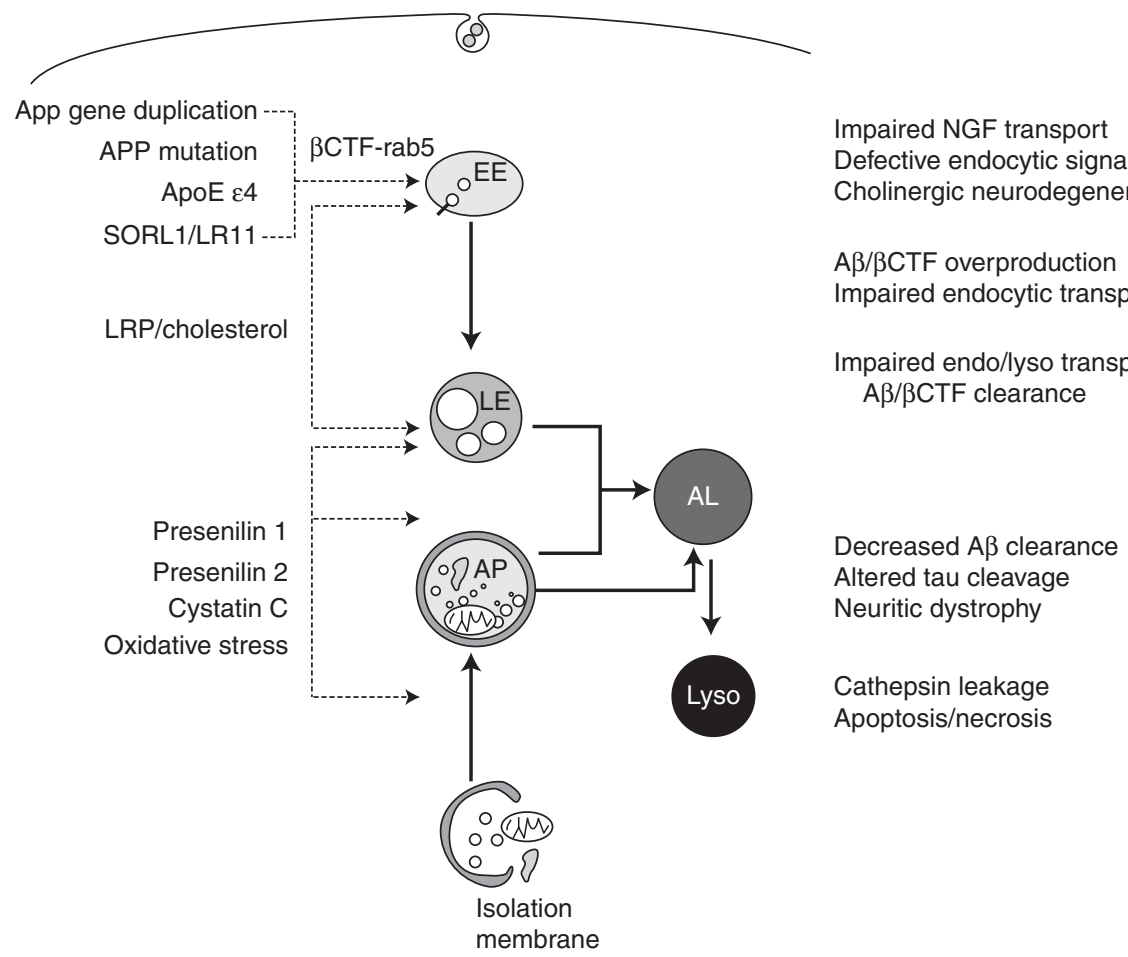

Figure 7. Dysfunction of autophagic and endocytic pathways to lysosomes driven by relevant genes and other risk factors in Alzheimer disease (left side of the diagram) causes or promotes pathophysiology critical to the development and progression of Alzheimer disease (right side of the diagram). See the text for further details.

to that seen at the earliest stages of sporadic AD, but beginning even earlier. Recently, these effects of increased App dosage were shown to be mediated specifically by the $\beta$-cleaved carboxy-terminal fragment of APP, $\beta$ CTF (Jiang et al. 2010), which binds to a complex of signaling molecules on endosomes that pathologically activates rab5 (S Kim and RA Nixon, unpubl.). It is this abnormal rab5 activation that causes protein and lipid accumulation in endosomes, slowed lysosomal degradation of endocytic cargoes, endosome swelling (Cataldo et al. 2008), and disrupted retrograde transport of endosomes (S Kim and RA Nixon, unpubl.). Interactions between FAD-mutant forms of APP and APP binding protein (APP-BP1) on endosomes also initiate pathological rab5 activation, which was shown to promote a neuronal apoptosis cascade (Laifenfeld et al. 2007).

Acceleration of endosome pathology is also seen in individuals who inherit the $\varepsilon 4$ allele of
APOE, a key mediator of neuronal cholesterol transport and the major genetic risk factor for late-onset AD (Cataldo et al. 2000). Moreover, among a very few additional pathological conditions associated with $\mathrm{AD}$-like endosomal pathology are APP transgenic mice fed elevated dietary cholesterol and individuals with Niemann-Pick type C (NPC), a disorder of cholesterol homeostasis. High dietary LDLcholesterol and overexpression of its receptor ApoE (particularly ApoE \&4) elevate $\beta$ CTF levels (Ji et al. 2006; Cossec et al. 2010), and these levels are also elevated in NPC, DS, and $\mathrm{AD}$, particularly in early-onset forms of $\mathrm{AD}$ caused by certain mutations of APP. The downstream consequences of $\beta$ CTF-mediated rab5 activation and abnormal endosomal signaling for $\mathrm{AD}$ progression are many, as discussed later. Although less well characterized, a growing number of $\mathrm{AD}$ risk genes for late-onset $\mathrm{AD}$ identified through genome-wide screens and 
association studies have direct links to endocytic regulation (Seshadri et al. 2010; Hollingworth et al. 2011; Hu et al. 2011).

The genetics of other neurological diseases further support a close connection between disruption of lysosomal network function and selective vulnerability to neurodegeneration (Nixon et al. 2008). Lysosomal storage disorders involving primary defects in lysosome function commonly exhibit prominent neurodegenerative phenotypes, including neuritic dystrophies closely resembling the ultrastructural morphologies of dystrophic neurites in $\mathrm{AD}$ and, in some of these disorders, neurofibrillary tangles as well as increased amyloidogenic processing of APP and diffuse $\beta$-amyloid deposits (Ryazantsev et al. 2007; Ohmi et al. 2009; Bellettato et al. 2010). Inherited defects in the endocytic pathway are also associated with neurodegenerative disorders at a high frequency (Nixon 2004; Nixon et al. 2008; Rusten et al. 2008; Zhang 2008).

Biology of Lysosomal Network Dysregulation in $\mathrm{AD}$ and Its Pathological Consequences

\section{Neuritic Dystrophy}

Endocytosis and autophagy are highly active at synaptic terminals and axons and generate large numbers of endosomes and autophagosomes, representing a considerable burden of retrograde organelle trafficking to the perikaryon (Overly et al. 1996). Transport and autophagy must, therefore, be especially efficient to prevent "traffic jams." In healthy neurons, these mechanisms are, in fact, exceptionally efficient, as evidenced by a scarcity of autophagy-related intermediates, a high autophagic clearance capacity, and the rapidity with which axonal AVs accumulate when their clearance is impeded (Nixon et al. 2011), but they are also highly vulnerable to disruption (Boland et al. 2008; Cai et al. 2010; Lee et al. 2011a).

$\mathrm{AVs}$ and lysosomes constitute more than 95\% of the organelles in dystrophic neuritic swellings in $\mathrm{AD}$ and $\mathrm{AD}$ mouse models, implying a cargo-specific defect in axonal transport, rather than a global one. Indeed, when lysosomal proteolysis is inhibited by blocking acidification or directly inhibiting cathepsins, axonal transport of autophagy-related compartments is selectively slowed and intermittently interrupted. These organelles then accumulate selectively within axon swellings that acquire additional AD-like features, including local cytoskeletal protein hyperphosphorylation and ubiquitin immunolabeling (Lee et al. 2011a). These observations suggest how PS1 mutations, which impede lysosomal acidification (Lee et al. 2010), may markedly accelerate and amplify neuritic dystrophy in $\mathrm{AD}$.

Similar neuritic dystrophy eventually develops in all forms of AD and in mouse AD models where only FAD-causing mutant APP is overexpressed. In these cases, the mechanism is not yet clear. $A \beta$ administered directly into brains of wild-type rodents does not induce neuritic dystrophy, despite diffuse amyloid deposition (Frautschy et al. 1996, 1998), raising the possibility that other APP metabolites within neuronal compartments besides or in addition to $\mathrm{A} \beta$ could be important to the development of neuritic dystrophy. In this regard, elevated $\beta C T F$ levels induced by APP overexpression, elevated dietary cholesterol, or overexpression of its receptor ApoE (particularly ApoE ع4) can upregulate endocytosis and enlarge endosomes (Laifenfeld et al. 2007; Chen et al. 2010; Cossec et al. 2010), leading to impaired endosome retrograde transport (S Kim and RA Nixon, unpubl.). Accelerated endocytosis also increases protein and lipid accumulation in endosomes and slows lysosomal degradation of endocytic cargoes (Cataldo et al. 2008), leading to lysosomal instability and neurodegeneration, as discussed below.

\section{Protein Clearance Failure and Amyloidogenesis}

In APP transgenic mouse models of AD, undigested autophagy substrates including LC3-II, p62, and ubiquitinated proteins accumulate in neuronal AVs, establishing that autophagic protein turnover in lysosomes is impeded (Yang et al. 2011). This general failure to clear autophagy substrates affects clearance of various proteins relevant to $\mathrm{AD}$ pathogenesis, including 
Y. Ihara et al.

$\mathrm{A} \beta$, tau, and other factors, such as damaged mitochondria and activated caspases, that promote cell death (Yang et al. 2008).

Autophagy sequesters and digests unneeded or damaged organelles, some of which are APP-rich (Pickford et al. 2008). AVs are also enriched in APP substrates and secretases and, during autophagy, $A \beta$ peptide is generated from APP (Yu et al. 2005), although it is subsequently degraded in lysosomes under normal circumstances (Heinrich et al. 1999; Bahr et al. 2002; Florez-McClure et al. 2007). Although less well studied as "A $\beta$ degrading proteases" than the zinc metallopeptidase family (Guenette 2003; Eckman et al. 2005), cathepsins are considered an important route for $\mathrm{A} \beta$ /amyloid clearance (Mueller-Steiner et al. 2006; Nixon 2007; Butler et al. 2011) and human neurons may be particularly dependent on this mechanism (LeBlanc et al. 1999; reviewed in Saido and Leissring 2011). Chronic low-level stimulation of autophagy through peripheral administration of rapamycin or other agents (Tian et al. 2011), or enhancing lysosomal proteolysis selectively (Sun et al. 2008; Yang et al. 2011), can markedly diminish $A \beta$ levels and amyloid load in APP transgenic mice, underscoring the importance of lysosomal clearance of $A \beta$.

Endocytic pathway up-regulation in $\mathrm{AD}$ stemming in part from pathological rab 5 activation generates higher levels of $\mathrm{A} \beta$ (Mathews et al. 2002; Grbovic et al. 2003) that must be cleared in part by lysosomes. Pathological rab5 activation, which in Down syndrome is dependent on $\beta$ CTF generation (Jiang et al. 2010), can up-regulate endocytosis in a manner functionally equivalent to the elevated endocytosis associated with increased synaptic activity, which is considered a source of $A \beta$ generation (Cirrito et al. 2008). An unknown amount of A $\beta$ produced in endosomes reaches lysosomes directly or via production during autophagy (Nixon 2007), and accumulated AVs and MVBs appear to be the major intracellular reservoirs of $A \beta$ immunoreactivity in $\mathrm{AD}$ brain (Takahashi et al. 2002; Yu et al. 2005). The acidic environment in lysosomes is particularly favorable for the initial stages of $A \beta$ oligomerization (Peralvarez-Marin et al. 2008).

\section{Tauopathy}

Neurofibrillary tangles composed of tau proteins in a hyperphosphorylated state are rarely observed in abundance except in AD and a limited number of aging-related tauopathies. However, they are a prominent feature in at least two lysosomal disorders, NPC and mucopolysaccharidosis type IIB (MPS IIB; Ohmi et al. 2009), and in a mouse model of MPS IIB (Ryazantsev et al. 2007). In NPC, which arises from a defect in endosomal trafficking of cholesterol and the accumulation of unesterified cholesterol in late endosomes/lysosomes, additional features associated with $\mathrm{AD}$ are seen, including allele-selective influences of the APOE genotype on pathology and increased amyloidogenic processing of APP (Nixon 2004). The mechanisms explaining this connection are unclear, but tau has been found to be an autophagy substrate, at least when overexpressed (Berger et al. 2006). Incomplete charperone-mediated autophagy of tau generates fragments that aggregate and are cleared by macroautophagy (Wang et al. 2009). Moreover, autophagy preferentially degrades a caspase-cleaved fragment of tau implicated in tau neurotoxicity (Dolan et al. 2010). Consistent with these findings, rapamycin induction of autophagy reduces tau pathology in the triple transgenic $\mathrm{AD}$ mouse model (Caccamo et al. 2010), whereas in other models, autophagic-lysosomal dysfunction amplifies tau pathology and tau neurotoxicity (Hamano et al. 2008; Khurana et al. 2010).

\section{Synaptic Dysfunction}

Pathological Rab5 activation driving endocytic dysfunction in $\mathrm{AD}$ may negatively impact longterm potentiation (LTP) and long-term depression (LTD) aspects of synaptic plasticity closely associated with learning and memory (Kessels et al. 2009). LTD induction requires surface removal of AMPA receptors driven by their Rab5-dependent internalization (Brown et al. 2005b). Conversely, deletion of the neuronal rab5 GEF, rin1, reduces rab5 activation, increases LTP induction in the amygdala, and enhances fear learning and memory, most likely by increasing surface levels of AMPA receptors 
(Dhaka et al. 2003). Autophagy may also modulate synaptic plasticity, which involves structural remodeling of nerve terminals (Boland et al. 2006) and the trafficking and degradation of receptors and other synaptic proteins (Leil et al. 2004; Rowland et al. 2006).

\section{Neurodegeneration}

A close connection between lysosomal network dysfunction and mechanisms of neurodegeneration is well documented (McCray et al. 2008; Nixon et al. 2008; Bellettato et al. 2010; Cherra et al. 2010). Deprived of the cytoprotective functions of autophagy, neurons, which cannot dilute toxic protein buildup by cell division, are particularly vulnerable to potentially toxic mutant, oxidized and aggregated proteins and peptide fragments. An important possible outcome of the accumulation of the latter in lysosomes is increased membrane permeability and release of hydrolases into the cytoplasm, even from otherwise intact lysosomes (Kroemer et al. 2005). Cataclysmic disruption of lysosomal membranes releases hydrolases that act as both the trigger and executioner in rapid necrosis (Syntichaki et al. 2003; Kroemer et al. 2005), whereas slow release of cathepsins more likely operates through signaling pathways to trigger apoptosis (Kroemer et al. 2005).

By up-regulating endocytosis, high dietary LDL-cholesterol and overexpression of its receptor ApoE (particularly ApoE ع4) elevate $\beta C T F$ levels and increase delivery of $A \beta 1-42$ to lysosomes in cellular model systems (Ji et al. 2006; Cossec et al. 2010). Accumulation of $A \beta 1-42$, which is less efficiently degraded than $A \beta 1-40$ owing to its strong propensity to aggregate, causes leakage of lysosomal enzymes into the cytosol prior to other morphological signs of cellular toxicity in vitro (Yang et al. 1998; Glabe 2001). Consistent with these findings, strong overexpression of human $\mathrm{A} \beta 42$, but not $\mathrm{A} \beta 40$, in Drosophila neurons induces age-related accumulation of $A \beta$ in autolysosomes and neurotoxicity (Ling et al. 2009). A 342 -induced neurotoxicity is further enhanced by autophagy activation and is partially rescued by autophagy inhibition. Expression of the ApoE $\varepsilon 4$ allele, but not ApoE $\varepsilon 3$, in mice administered a neprilysin inhibitor increases $\mathrm{A} \beta$ immunoreactivity in lysosomes and causes neurodegeneration of hippocampal CA1, entorhinal, and septal neurons (Belinson et al. 2008). ApoE $\varepsilon 4$ that trafficks to lysosomes more readily than ApoE \&3, promotes leakage of acid hydrolases, and induces apoptosis in cultured neuronal cells by forming membranedamaging intermediates in the low-pH environment (Ji et al. 2002).

Beyond influencing $A \beta$ generation and toxicity, defective endosome functioning plays a crucial $A \beta$-independent role in the failure of retrograde NGF signaling that leads to basal forebrain cholinergic neuron degeneration in the Ts65Dn mouse model of DS (Cooper et al. 2001; Delcroix et al. 2004). Proteins known to play roles in both endocytosis regulation and cell survival decisions link the endosome dysregulation seen in $\mathrm{AD}$ to cell death cascade signaling (Vito et al. 1996, 1999; Missotten et al. 1999; Chen et al. 2000; Gout et al. 2000).

\section{Remediating Lysosomal Network Dysfunction as AD Therapy}

Recent evidence supports the value of targeting autophagy efficiency as a possible therapeutic strategy for AD. Peripheral administration of rapamycin to strongly stimulate autophagy substantially reduces amyloid deposition and tau pathology in both APP and triple transgenic mouse models of AD pathology (Caccamo et al. 2010; Spilman et al. 2010; Tian et al. 2011). Autophagy induction also has beneficial effects in transgenic models of several aging-related neurodegenerative diseases (Garcia-Arencibia et al. 2010). Stimulating lysosomal proteolytic efficiency in the TgCRND8 APP mouse model by deleting an endogenous inhibitor of lysosomal cysteine proteases (cystatin B) rescues lysosomal pathology, eliminates abnormal autolysosomal accumulation of autophagy substrates, including $A \beta$, decreases $A \beta$ and amyloid deposition, and ameliorates learning and memory deficits (Yang et al. 2011). Similar therapeutic effects, including restoration of synaptic functions, are seen in APP mouse models after 
Y. Ihara et al.

deleting cystatin C (Sun et al. 2008), by overexpressing cathepsin B (Mueller-Steiner et al. 2006), or by enhancing its activity (Butler et al. 2011). Collectively, these observations support the pathogenic significance of autophagic-lysosomal dysfunction in $\mathrm{AD}$ and specifically the importance of deficient lysosomal proteolysis.

\section{CONCLUSION}

As postmitotic cells, neurons are especially reliant on the lysosomal network to sort and clear normal and damaged proteins and support vital signaling functions. Not surprisingly, a defective endosomal-lysosomal pathway and certain autophagy-related genes are being linked with an unusually high frequency to neurodegenerative diseases, and the mechanistic relationship to neurodegeneration is becoming increasingly well established. Driven by the same genetic and environmental risk factors implicated in the $A \beta /$ amyloid cascade hypothesis, a continuum of highly characteristic pathological changes in the lysosomal network evolves during $\mathrm{AD}$, including dysregulation of endocytosis, increased lysosome biogenesis, and progressive failure of lysosomal proteolysis and autophagy. These deficits cripple neuronal functions critical for synaptic plasticity and neuron survival, lead to the hallmark neuritic dystrophy of $\mathrm{AD}$, promote accumulation of toxic proteins-including $A \beta$, tau, activated caspases, and other cell death-promoting proteins-and initiate multiple neurodegenerative cascades. Remediation of lysosomal network dysfunction by several different approaches has been shown to have significant ameliorative effects on pathological and cognitive deficits in animal models of $\mathrm{AD}$, underscoring the pathogenic significance of this dysfunction and the promise of therapeutic strategies targeting the lysosomal network in $\mathrm{AD}$ and other neurodegenerative disorders.

\section{ACKNOWLEDGMENTS}

The work of the Ihara laboratory on ubiquitin and PHF was carried out from 1985 to 1993, and Dr. Ihara thanks all laboratory members from that period (Department of Clinical Physiology, Tokyo Metropolitan Institute of Gerontology; Department of Neuropathology, Faculty of Medicine, University of Tokyo). In particular, the preparation of the DF2 antibody and identification of ubiquitin in PHF was performed collaboratively with Dr Hiroshi Mori, Department of Neuroscience, Osaka City University Graduate School of Medicine. For the introduction and section on autophagy and the lysosomal system, the assistance of Nicole Piorkowski and Corrinne Peterhoff in manuscript and figure preparation is gratefully acknowledged. Research from the Nixon laboratories is supported by the National Institute on Aging.

\section{REFERENCES}

* Reference is also in this collection.

Anderton BH, Breinburg D, Downes MJ, Green PJ, Tomlinson BE, Ulrich J, Wood JN, Kahn J. 1982. Monoclonal antibodies show that neurofibrillary tangles and neurofilaments share antigenic determinants. Nature 298: 84-86.

Arias E, Cuervo AM. 2011. Chaperone-mediated autophagy in protein quality control. Curr Opin Cell Biol 23: 184189.

Athan ES, Lee JH, Arriaga A, Mayeux RP, Tycko B. 2002. Polymorphisms in the promoter of the human APP gene: Functional evaluation and allele frequencies in Alzheimer disease. Arch Neurol 59: 1793-1799.

Babst M, Sato TK, Banta LM, Emr SD. 1997. Endosomal transport function in yeast requires a novel AAA-type ATPase, Vps4p. EMBO J 16: 1820-1831.

Bahr BA, Bendiske J. 2002. The neuropathogenic contributions of lysosomal dysfunction. J Neurochem 83: 481-489.

Bancher C, Grundke-Iqbal I, Iqbal K, Fried VA, Smith HT, Wisniewski HM. 1991. Abnormal phosphorylation of tau precedes ubiquitination in neurofibrillary pathology of Alzheimer disease. Brain Res 539: 11-18.

Belin AC, Westerlund M. 2008. Parkinson's disease: A genetic perspective. FEBS J 275: 1377-1383.

Belinson H, Lev D, Masliah E, Michaelson DM. 2008. Activation of the amyloid cascade in apolipoprotein E4 transgenic mice induces lysosomal activation and neurodegeneration resulting in marked cognitive deficits. J Neurosci 28: 4690-701.

Bellettato CM, Scarpa M. 2010. Pathophysiology of neuropathic lysosomal storage disorders. J Inherit Metab Dis 33: 347-362.

Bence NF, Sampat RM, Kopito RR. 2001. Impairment of the ubiquitin-proteasome system by protein aggregation. Science 292: 1552-1555.

Benzing WC, Mufson EJ, Armstrong DM. 1993. Alzheimer's disease-like dystrophic neurites characteristically associated with senile plaques are not found within other 
neurodegenerative diseases unless amyloid $\beta$-protein deposition is present. Brain Res 606: 10-18.

Berger Z, Ravikumar B, Menzies FM, Oroz LG, Underwood BR, Pangalos MN, Schmitt I, Wullner U, Evert BO, O'Kane CJ, et al. 2006. Rapamycin alleviates toxicity of different aggregate-prone proteins. Hum Mol Genet 15: 433-442.

Berke SJ, Paulson HL. 2003. Protein aggregation and the ubiquitin proteasome pathway: Gaining the UPPer hand on neurodegeneration. Curr Opin Genet Dev 13: 253-261.

Bertram L, Hiltunen M, Parkinson M, Ingelsson M, Lange C, Ramasamy K, Mullin K, Menon R, Sampson AJ, Hsiao MY, et al. 2005. Family-based association between Alzheimer's disease and variants in UBQLN1. New Engl $J$ Med 352: 884-894.

Bingol B, Sheng M. 2011. Deconstruction for reconstruction: The role of proteolysis in neural plasticity and disease. Neuron 69: 22-32.

Boland B, Nixon RA. 2006. Neuronal macroautophagy: From development to degeneration. Mol Aspects Med 27: $503-519$.

Boland B, Kumar A, Lee S, Platt FM, Wegiel J, Yu WH, Nixon RA. 2008. Autophagy induction and autophagosome clearance in neurons: Relationship to autophagic pathology in Alzheimer's disease. J Neurosci 28: 6926-6937.

Brion JP, Couck AM, Passareiro E, Flament-Durand J. 1985. Neurofibrillary tangles of Alzheimer's disease: An immunohistochemical study. J Submicrosc Cytol 17: 89-96.

Brown MR, Bondada V, Keller JN, Thorpe J, Geddes JW. 2005a. Proteasome or calpain inhibition does not alter cellular tau levels in neuroblastoma cells or primary neurons. J Alzheimer's Dis 7: 15-24.

Brown TC, Tran IC, Backos DS, Esteban JA. 2005b. NMDA receptor-dependent activation of the small GTPase Rab5 drives the removal of synaptic AMPA receptors during hippocampal LTD. Neuron 45: 81-94.

Butler D, Hwang J, Estick C, Nishiyama A, Kumar SS, Baveghems C, Young-Oxendine HB, Wisniewski ML, Charalambides A, Bahr BA. 2011. Protective effects of positive lysosomal modulation in Alzheimer's disease transgenic mouse models. PLoS One 6: e20501.

Caccamo A, Majumder S, Richardson A, Strong R, Oddo S. 2010. Molecular interplay between mammalian target of rapamycin (mTOR), amyloid- $\beta$, and Tau: Effects on cognitive impairments. J Biol Chem 285: 13107-13120.

Cai Q, Lu L, Tian JH, Zhu YB, Qiao H, Sheng ZH. 2010. Snapin-regulated late endosomal transport is critical for efficient autophagy-lysosomal function in neurons. Neuron 68: 73-86.

Cardozo C, Michaud C. 2002. Proteasome-mediated degradation of tau proteins occurs independently of the chymotrypsin-like activity by a nonprocessive pathway. Arch Biochem Biophys 408: 103-110.

Cataldo AM, Nixon RA. 1990. Enzymatically active lysosomal proteases are associated with amyloid deposits in Alzheimer brain. Proc Natl Acad Sci 87: 3861-3865.

Cataldo AM, Paskevich PA, Kominami E, Nixon RA. 1991. Lysosomal hydrolases of different classes are abnormally distributed in brains of patients with Alzheimer disease. Proc Natl Acad Sci 88: 10998-11002.
Cataldo AM, Barnett JL, Pieroni C, Nixon RA. 1997. Increased neuronal endocytosis and protease delivery to early endosomes in sporadic Alzheimer's disease: Neuropathologic evidence for a mechanism of increased $\beta$-amyloidogenesis. J Neurosci 17: 6142-6151.

Cataldo AM, Peterhoff CM, Troncoso JC, Gomez-Isla T, Hyman BT, Nixon RA. 2000. Endocytic pathway abnormalities precede amyloid $\beta$ deposition in sporadic Alzheimer's disease and Down syndrome: Differential effects of APOE genotype and presenilin mutations. Am J Pathol 157: 277-286.

Cataldo AM, Peterhoff CM, Schmidt SD, Terio NB, Duff K, Beard M, Mathews PM, Nixon RA. 2004. Presenilin mutations in familial Alzheimer disease and transgenic mouse models accelerate neuronal lysosomal pathology. J Neuropathol Exp Neurol 63: 821-830.

Cataldo AM, Mathews PM, Boiteau AB, Hassinger LC, Peterhoff CM, Jiang Y, Mullaney K, Neve RL, Gruenberg J, Nixon RA. 2008. Down syndrome fibroblast model of Alzheimer-related endosome pathology. Accelerated endocytosis promotes late endocytic defects. Am J Pathol 173: $370-384$.

Chen B, Borinstein SC, Gillis J, Sykes VW, Bogler O. 2000. The glioma-associated protein SETA interacts with AIP1/Alix and ALG-2 and modulates apoptosis in astrocytes. J Biol Chem 275: 19275-19281.

Chen X, Wagener JF, Morgan DH, Hui L, Ghribi O, Geiger JD. 2010. Endolysosome mechanisms associated with Alzheimer's disease-like pathology in rabbits ingesting cholesterol-enriched diet. J Alzheimer's Dis 22: 12891303.

Cherra SJ 3rd, Dagda RK, Chu CT. 2010. Review: Autophagy and neurodegeneration: Survival at a cost? Neuropathol Appl Neurobiol 36: 125-132.

Choi J, Levey AI, Weintraub ST, Rees HD, Gearing M, Chin LS, Li L. 2004. Oxidative modifications and downregulation of ubiquitin carboxyl-terminal hydrolase L1 associated with idiopathic Parkinson's and Alzheimer's diseases. J Biol Chem 279: 13256-13264.

Ciechanover A, Finley D, Varshavsky A. 1984. Ubiquitin dependence of selective protein degradation demonstrated in the mammalian cell cycle mutant ts85. Cell 37: 57-66.

Cirrito JR, Kang J-E, Lee J, Stewart FR, Verges DK, Silverio LM, Bu G, Mennerick S, Holtzman DM. 2008. Endocytosis is required for synaptic activity-dependent release of amyloid- $\beta$ in vivo. Neuron 58: $42-51$.

Cooper JD, Salehi A, Delcroix JD, Howe CL, Belichenko PV, Chua-Couzens J, Kilbridge JF, Carlson EJ, Epstein CJ, Mobley WC. 2001. Failed retrograde transport of NGF in a mouse model of Down's syndrome: Reversal of cholinergic neurodegenerative phenotypes following NGF infusion. Proc Natl Acad Sci 98: 10439-10444.

Cossec JC, Simon A, Marquer C, Moldrich RX, Leterrier C, Rossier J, Duyckaerts C, Lenkei Z, Potier MC. 2010. Clathrin-dependent APP endocytosis and $A \beta$ secretion are highly sensitive to the level of plasma membrane cholesterol. Biochim Biophys Acta 1801: 846-852.

Cripps D, Thomas SN, Jeng Y, Yang F, Davies P, Yang AJ. 2006. Alzheimer disease-specific conformation of hyperphosphorylated paired helical filament-Tau is polyubiquitinated through Lys-48, Lys-11, and Lys-6 ubiquitin conjugation. J Biol Chem 281: 10825-10838. 
Y. Ihara et al.

Cuervo AM. 2004. Autophagy: Many paths to the same end Mol Cell Biochem 263: 55-72.

Cuervo AM, Palmer A, Rivett AJ, Knecht E. 1995. Degradation of proteasomes by lysosomes in rat liver. Eur J Biochem 227: 792-800.

David DC, Layfield R, Serpell L, Narain Y, Goedert M, Spillantini MG. 2002. Proteasomal degradation of tau protein. J Neurochem 83: 176-185.

Delcroix JD, Valletta JS, Wu C, Hunt SJ, Kowal AS, Mobley WC. 2003. NGF signaling in sensory neurons: Evidence that early endosomes carry NGF retrograde signals. Neuron 39: 69-84.

Delcroix JD, Valletta J, Wu C, Howe CL, Lai CF, Cooper JD, Belichenko PV, Salehi A, Mobley WC. 2004. Trafficking the NGF signal: Implications for normal and degenerating neurons. Prog Brain Res 146: 3-23.

Dhaka A, Costa RM, Hu H, Irvin DK, Patel A, Kornblum HI, Silva AJ, O'Dell TJ, Colicelli J. 2003. The RAS effector RIN1 modulates the formation of aversive memories. $J$ Neurosci 23: 748-757.

Dickey CA, Yue M, Lin WL, Dickson DW, Dunmore JH, Lee WC, Zehr C, West G, Cao S, Clark AM, et al. 2006. Deletion of the ubiquitin ligase CHIP leads to the accumulation, but not the aggregation, of both endogenous phospho- and caspase-3-cleaved tau species. J Neurosci 26: 6985-6996.

Dikic I, Johansen T, Kirkin V. 2010. Selective autophagy in cancer development and therapy. Cancer Res 70: 3431-3434.

Dolan PJ, Johnson GV. 2010. A caspase cleaved form of tau is preferentially degraded through the autophagy pathway. J Biol Chem 285: 21978-21987.

Eckman EA, Eckman CB. 2005. A $\beta$-degrading enzymes: Modulators of Alzheimer's disease pathogenesis and targets for therapeutic intervention. Biochem Soc Trans 33: 1101-1105.

Finley D, Ciechanover A, Varshavsky A. 1984. Thermolability of ubiquitin-activating enzyme from the mammalian cell cycle mutant ts85. Cell 37: 43-55.

Fischer DF, De Vos RA, Van Dijk R, De Vrij FM, Proper EA, Sonnemans MA, Verhage MC, Sluijs JA, Hobo B, Zouambia M, et al. 2003. Disease-specific accumulation of mutant ubiquitin as a marker for proteasomal dysfunction in the brain. FASEB J 17: 2014-2024.

Fischer DF, van Dijk R, van Tijn P, Hobo B, Verhage MC, van der Schors RC, Li KW, van Minnen J, Hol EM, van Leeuwen FW. 2009. Long-term proteasome dysfunction in the mouse brain by expression of aberrant ubiquitin. Neurobiol Aging 30: 847-863.

Florez-McClure ML, Hohsfield LA, Fonte G, Bealor MT, Link CD. 2007. Decreased insulin-receptor signaling promotes the autophagic degradation of $\beta$-amyloid peptide in C. elegans. Autophagy 3: 569-580.

Fortun J, Dunn WA Jr, Joy S, Li J, Notterpek L. 2003. Emerging role for autophagy in the removal of aggresomes in Schwann cells. J Neurosci 23: 10672-10680.

Frautschy SA, Yang F, Calderon L, Cole GM. 1996. Rodent models of Alzheimer's disease: Rat A $\beta$ infusion approaches to amyloid deposits. Neurobiol Aging 17: 311-321.
Frautschy SA, Horn DL, Sigel JJ, Harris-White ME, Mendoza JJ, Yang F, Saido TC, Cole GM. 1998. Protease inhibitor coinfusion with amyloid $\beta$-protein results in enhanced deposition and toxicity in rat brain. J Neurosci 18: $8311-8321$.

Gallastegui N, Groll M. 2010. The 26 S proteasome: Assembly and function of a destructive machine. Trends Biochem Sci 35: 634-642.

Garcia-Arencibia M, Hochfeld WE, Toh PP, Rubinsztein DC. 2010. Autophagy, a guardian against neurodegeneration. Semin Cell Dev Biol 21: 691-698.

Ginsberg SD, Alldred MJ, Counts SE, Cataldo AM, Neve RL, Jiang Y, Wuu J, Chao MV, Mufson EJ, Nixon RA, et al. 2010. Microarray analysis of hippocampal CA1 neurons implicates early endosomal dysfunction during Alzheimer's disease progression. Biol Psychiat 68: 885-893.

Glabe C. 2001. Intracellular mechanisms of amyloid accumulation and pathogenesis in Alzheimer's disease. $J$ Mol Neurosci 17: 137-145.

Goldberg AL. 2003. Protein degradation and protection against misfolded or damaged proteins. Nature 426: 895-899.

Gómez-Isla T, Hollister R, West H, Mui S, Growdon JH, Petersen RC, Parisi JE, Hyman BT. 1997. Neuronal loss correlates with but exceeds neurofibrillary tangles in Alzheimer's disease. Ann Neurol 41: 17-24.

Gonatas NK. 1967. Neocortical synapses in a presenile dementia. J Neuropathol Exp Neurol 26: 150-151.

Gong B, Cao Z, Zheng P, Vitolo OV, Liu S, Staniszewski A, Moolman D, Zhang H, Shelanski M, Arancio O. 2006. Ubiquitin hydrolase Uch-L1 rescues $\beta$-amyloid-induced decreases in synaptic function and contextual memory. Cell 126: 775-788.

Gordon PB, Seglen PO. 1988. Prelysosomal convergence of autophagic and endocytic pathways. Biochem Biophys Res Commun 151: 40-47.

Gout I, Middleton G, Adu J, Ninkina NN, Drobot LB, Filonenko V, Matsuka G, Davies AM, Waterfield M, Buchman VL. 2000. Negative regulation of PI 3-kinase by Ruk, a novel adaptor protein. EMBO J 19: 4015-4025.

Grbovic OM, Mathews PM, Jiang Y, Schmidt SD, Dinakar R, Summers-Terio NB, Ceresa BP, Nixon RA, Cataldo AM. 2003. Rab5-stimulated up-regulation of the endocytic pathway increases intracellular $\beta$-cleaved amyloid precursor protein carboxyl-terminal fragment levels and A $\beta$ production. J Biol Chem 278: 31261-31268.

Greer PL, Hanayama R, Bloodgood BL, Mardinly AR, Lipton DM, Flavell SW, Kim TK, Griffith EC, Waldon Z, Maehr R, et al. 2010. The Angelman syndrome protein Ube3A regulates synapse development by ubiquitinating arc. Cell 140: 704-716.

Grundke-Iqbal I, Iqbal K, Quinlan M, Tung YC, Zaidi MS, Wisniewski HM. 1986. Microtubule-associated protein tau. A component of Alzheimer paired helical filaments. J Biol Chem 261: 6084-6089.

Grune T, Shringarpure R, Sitte N, Davies K. 2001. Age-related changes in protein oxidation and proteolysis in mammalian cells. J Gerontol A Biol Sci Med Sci 56: B459-B467.

Guenette SY. 2003. Mechanisms of $A \beta$ clearance and catabolism. Neuromol Med 4: 147-160. 
Haapasalo A, Viswanathan J, Bertram L, Soininen H, Tanzi RE, Hiltunen M. 2010. Emerging role of Alzheimer's disease-associated ubiquilin-1 in protein aggregation. Biochem Soc Trans 38: 150-155.

Haas AL, Bright PM. 1985. The immunochemical detection and quantitation of intracellular ubiquitin-protein conjugates. J Biol Chem 260: 12464-12473.

Hamano T, Gendron TF, Causevic E, Yen SH, Lin WL, Isidoro C, Deture M, Ko LW. 2008. Autophagic-lysosomal perturbation enhances tau aggregation in transfectants with induced wild-type tau expression. Eur J Neurosci 27: 1119-30.

Hasegawa M, Morishima-Kawashima M, Takio K, Suzuki M, Titani K, Ihara Y. 1992. Protein sequence and mass spectrometric analyses of tau in the Alzheimer's disease brain. J Biol Chem 267: 17047-17054.

Hasegawa M, Fujiwara H, Nonaka T, Wakabayashi K, Takahashi H, Lee VM, Trojanowski JQ, Mann D, Iwatsubo T. 2002. Phosphorylated $\alpha$-synuclein is ubiquitinated in $\alpha$-synucleinopathy lesions. J Biol Chem 277: 4907149076.

Hegde AN, Goldberg AL, Schwartz JH. 1993. Regulatory subunits of cAMP-dependent protein kinases are degraded after conjugation to ubiquitin: A molecular mechanism underlying long-term synaptic plasticity. Proc Natl Acad Sci 90: 7436-7440.

Hegde AN, Inokuchi K, Pei W, Casadio A, Ghirardi M, Chain DG, Martin KC, Kandel ER, Schwartz JH. 1997. Ubiquitin C-terminal hydrolase is an immediate-early gene essential for long-term facilitation in Aplysia. Cell 89: $115-126$.

Heinrich M, Wickel M, Schneider-Brachert W, Sandberg C, Gahr J, Schwandner R, Weber T, Saftig P, Peters C, Brunner J, et al. 1999. Cathepsin D targeted by acid sphingomyelinase-derived ceramide. EMBO J 18: 5252-5263.

Hollingworth P, Harold D, Jones L, Owen MJ, Williams J. 2011. Alzheimer's disease genetics: Current knowledge and future challenges. Int J Geriatr Psychiat 26: 793-802.

Hsia AY, Masliah E, McConlogue L, Yu GQ, Tatsuno G, Hu K, Kholodenko D, Malenka RC, Nicoll RA, Mucke L. 1999. Plaque-independent disruption of neural circuits in Alzheimer's disease mouse models. Proc Natl Acad Sci 96: 3228-3233.

Hu X, Pickering E, Liu YC, Hall S, Fournier H, Katz E, Dechairo B, John S, Van Eerdewegh P, Soares H. 2011 Meta-analysis for genome-wide association study identifies multiple variants at the BIN1 locus associated with late-onset Alzheimer's disease. PLoS One 6: el6616.

Hurley JH. 2010. The ESCRT complexes. Crit Rev Biochem Mol Biol 45: 463-487.

Ihara Y, Abraham C, Selkoe DJ. 1983. Antibodies to paired helical filaments in Alzheimer's disease do not recognize normal brain proteins. Nature 304: 727-729.

Ivy GO, Schottler F, Wenzel J, Baudry M, Lynch G. 1984 Inhibitors of lysosomal enzymes: Accumulation of lipofuscin-like dense bodies in the brain. Science 226: 985-987.

Iwatsubo T, Hasegawa M, Esaki Y, Ihara Y. 1992. Lack of ubiquitin immunoreactivities at both ends of neuropil threads-Possible bidirectional growth of neuropil threads. Am J Pathol 140: 277-282.
Ji ZS, Miranda RD, Newhouse YM, Weisgraber KH, Huang Y, Mahley RW. 2002. Apolipoprotein E4 potentiates amyloid $\beta$ peptide-induced lysosomal leakage and apoptosis in neuronal cells. J Biol Chem 277: 2182121828.

Ji ZS, Mullendorff K, Cheng IH, Miranda RD, Huang Y, Mahley RW. 2006. Reactivity of apolipoprotein E4 and amyloid $\beta$ peptide: Lysosomal stability and neurodegeneration. J Biol Chem 281: 2683-2692.

Jiang Y, Mullaney KA, Peterhoff CM, Che S, Schmidt SD, Boyer-Boiteau A, Ginsberg SD, Cataldo AM, Mathews PM, Nixon RA. 2010. Alzheimer's-related endosome dysfunction in Down syndrome is $A \beta$-independent but requires APP and is reversed by BACE-1 inhibition. Proc Natl Acad Sci 107: 1630-1635.

Jin M, Shepardson N, Yang T, Chen G, Walsh D, Selkoe DJ. 2011. Soluble amyloid $\beta$-protein dimers isolated from Alzheimer cortex directly induce Tau hyperphosphorylation and neuritic degeneration. Proc Natl Acad Sci 108: 5819-5824.

Keck S, Nitsch R, Grune T, Ullrich O. 2003. Proteasome inhibition by paired helical filament-tau in brains of patients with Alzheimer's disease. J Neurochem 85: $115-122$.

Keller JN, Hanni KB, Markesbery WR. 2000. Impaired proteasome function in Alzheimer's disease. J Neurochem 75: $436-439$.

Keller JN, Gee J, Ding Q. 2002. The proteasome in brain aging. Ageing Res Rev 1: 279-293.

Kelly BT, Owen DJ. 2011. Endocytic sorting of transmembrane protein cargo. Curr Opin Cell Biol 23: 404-412.

Kessels HW, Malinow R. 2009. Synaptic AMPA receptor plasticity and behavior. Neuron 61: 340-350.

Khurana V, Elson-Schwab I, Fulga TA, Sharp KA, Loewen CA, Mulkearns E, Tyynela J, Scherzer CR, Feany MB. 2010. Lysosomal dysfunction promotes cleavage and neurotoxicity of tau in vivo. PLoS Genet 6: e1001026.

Koike M, Shibata M, Waguri S, Yoshimura K, Tanida I, Kominami E, Gotow T, Peters C, von Figura K, Mizushima N, et al. 2005. Participation of autophagy in storage of lysosomes in neurons from mouse models of neuronal ceroid-lipofuscinoses (Batten disease). Am J Pathol 167: 1713-1728.

Kondo J, Honda T, Mori H, Hamada Y, Miura R, Ogawara M, Ihara Y. 1988. The carboxyl third of tau is tightly bound to paired helical filaments. Neuron 1: 827-834.

Korolchuk VI, Mansilla A, Menzies FM, Rubinsztein DC. 2009a. Autophagy inhibition compromises degradation of ubiquitin-proteasome pathway substrates. Mol Cell 33: $517-527$.

Korolchuk VI, Menzies FM, Rubinsztein DC. 2009b. A novel link between autophagy and the ubiquitin-proteasome system. Autophagy 5: 862-863.

Kosaka K. 1978. Lewy bodies in cerebral cortex, report of three cases. Acta Neuropathol 42: 127-134.

Kosik KS, Joachim CL, Selkoe DJ. 1986. Microtubule-associated protein tau (tau) is a major antigenic component of paired helical fragments in Alzheimer disease. Proc Natl Acad Sci 83: 4044-4048.

Kroemer G, Jaattela M. 2005. Lysosomes and autophagy in cell death control. Nat Rev Cancer 5: 886-97. 
Y. Ihara et al.

Kuzuhara S, Mori H, Izumiyama N, Yoshimura M, Ihara Y 1988. Lewy bodies are ubiquitinated. A light and electron microscopic immunocytochemical study. Acta Neuropathol 75: 345-353.

Laifenfeld D, Patzek LJ, McPhie DL, Chen Y, Levites Y, Cataldo AM, Neve RL. 2007. Rab5 mediates an amyloid precursor protein signaling pathway that leads to apoptosis. $J$ Neurosci 27: 7141-7153.

Lam YA, Pickart CM, Alban A, Landon M, Jamieson C, Ramage R, Mayer RJ, Layfield R. 2000. Inhibition of the ubiquitin-proteasome system in Alzheimer's disease. Proc Natl Acad Sci 97: 9902-9906.

Larsen KE, Sulzer D. 2002. Autophagy in neurons: A review. Histol Histopathol 17: 897-908.

LeBlanc AC, Goodyer CG. 1999. Role of endoplasmic reticulum, endosomal-lysosomal compartments, and microtubules in amyloid precursor protein metabolism of human neurons. J Neurochem 72: 1832-42.

Lee JH, Yu WH, Kumar A, Lee S, Mohan PS, Peterhoff CM, Marinez-Vicente M, Massey AG, Sovak G, Uchiyama Y, et al. 2010. Presenilin 1 (PS1) is required for v-ATPase targeting and autolysosome acidification: PS1 mutations in Alzheimer's disease disrupt lysosomal proteolysis and autophagy. Cell 141: 1146-1158.

Lee S, Sato Y, Nixon RA. 2011a. Lysosomal proteolysis inhibition selectively disrupts axonal transport of degradative organelles and causes an Alzheimer's-like axonal dystrophy. J Neurosci 31: 7817-7830.

Lee S, Saito Y, Nixon RA. 2011b. Primary lysosomal dysfunction causes cargo-specific deficits of axonal transport leading to Alzheimer's-like neuritic dystrophy. Autophagy 7: in press.

Leil TA, Chen ZW, Chang CS, Olsen RW. 2004. GABAA receptor-associated protein traffics $\mathrm{GABA}_{\mathrm{A}}$ receptors to the plasma membrane in neurons. J Neurosci 24: 11429-11438.

Levine B, Klionsky DJ. 2004. Development by self-digestion; molecular mechanisms and biological functions of autophagy. Dev Cell 6: 463-477.

Levine B, Mizushima N, Virgin HW. 2011. Autophagy in immunity and inflammation. Nature 469: 323-335.

Li S, Hong S, Shepardson NE, Walsh DM, Shankar GM, Selkoe D. 2009. Soluble oligomers of amyloid $\beta$ protein facilitate hippocampal long-term depression by disrupting neuronal glutamate uptake. Neuron 62: 788-801.

Lim JP, Gleeson PA. 2011. Macropinocytosis: An endocytic pathway for internalising large gulps. Immunol Cell Biol doi: 10.1038/icb.2011.20.

Ling D, Song HJ, Garza D, Neufeld TP, Salvaterra PM. 2009. A $\beta 42$-induced neurodegeneration via an age-dependent autophagic-lysosomal injury in Drosophila. PLoS One 4: e4201.

Lipinski MM, Zheng B, Lu T, Yan Z, Py BF, Ng A, Xavier RJ, Li C, Yankner BA, Scherzer CR, et al. 2010. Genome-wide analysis reveals mechanisms modulating autophagy in normal brain aging and in Alzheimer's disease. Proc Natl Acad Sci 107: 14164-14169.

Lopez-Salon M, Alonso M, Vianna MR, Viola H, Mello e Souza T, Izquierdo I, Pasquini JM, Medina JH. 2001. The ubiquitin-proteasome cascade is required for mammalian long-term memory formation. Eur J Neurosci 4: $1820-1826$.

Lowe J, Blanchard A, Morrell K, Lennox G, Reynolds L, Billett M, Landon M, Mayer RJ. 1988. Ubiquitin is a common factor in intermediate filament inclusion bodies of diverse type in man, including those of Parkinson's disease, Pick's disease, and Alzheimer's disease, as well as Rosenthal fibres in cerebellar astrocytomas, cytoplasmic bodies in muscle, and mallory bodies in alcoholic liver disease. J Pathol 155: 9-15.

* Mandelkow E-M, Mandelkow E. 2011. Biochemistry and cell biology of tau protein in neurofibrillary degeneration. Cold Spring Harb Perspect Med doi: 10.1101/ cshperspect.a006247.

Margallo-Lana M, Morris CM, Gibson AM, Tan AL, Kay DW, Tyrer SP, Moore BP, Ballard CG. 2004. Influence of the amyloid precursor protein locus on dementia in Down syndrome. Neurology 62: 1996-1998.

Masliah E, Mallory M, Deerinck T, DeTeresa R, Lamont S, Miller A, Terry RD, Carragher B, Ellisman M. 1993. Re-evaluation of the structural organization of the neuritic plaques in Alzheimer's disease. J Neuropathol Exp Neurol 52: 619-632.

Mathews PM, Guerra CB, Jiang Y, Grbovic OM, Kao BH, Schmidt SD, Dinakar R, Mercken M, Hille-Rehfeld A, Rohrer J, et al. 2002. Alzheimer's disease-related overexpression of the cation-dependent mannose 6-phosphate receptor increases $A \beta$ secretion: Role for altered lysosomal hydrolase distribution in $\beta$-amyloidogenesis. J Biol Chem 277: 5299-5307.

McCray BA, Taylor JP. 2008. The role of autophagy in agerelated neurodegeneration. Neurosignals 16: 75-84.

Missotten M, Nichols A, Rieger K, Sadoul R. 1999. Alix, a novel mouse protein undergoing calcium-dependent interaction with the apoptosis-linked-gene 2 (ALG-2) protein. Cell Death Differ 6: 124-129.

Mori H, Kondo J, Ihara Y. 1987. Ubiquitin is a component of paired helical filaments in Alzheimer's disease. Science 235: $1641-1644$.

Morimoto T, Ide T, Ihara Y, Tamura A, Kirino T. 1996. Transient ischemia depletes free ubiquitin in the gerbil hippocampal CA1 neurons. Am J Pathol 148: 249-257.

Morishima-Kawashima M, Hasegawa M, Takio K, Suzuki M, Titani K, Ihara Y. 1993. Ubiquitin is conjugated with amino-terminally processed tau in paired helical filaments. Neuron 10: 1151-1160.

Mueller-Steiner S, Zhou Y, Arai H, Roberson ED, Sun B, Chen J, Wang X, Yu G, Esposito L, Mucke L, et al. 2006. Antiamyloidogenic and neuroprotective functions of cathepsin B: Implications for Alzheimer's disease. Neuron 51: 703-714.

Mullins C, Bonifacino JS. 2001. The molecular machinery for lysosome biogenesis. Bioessays 23: 333-343.

Murayama S, Mori H, Ihara Y, Bouldin TW, Suzuki K, Tomonaga M. 1990a. Immunocytochemical and ultrastructural studies of lower motor neurons in amyotrophic lateral sclerosis. Ann Neurol 27: 137-148.

Murayama S, Mori H, Ihara Y, Tomonaga M. 1990b. Immunocytochemical and ultrastructural studies of Pick's disease. Ann Neurol 27: 394-405. 
Narendra D, Tanaka A, Suen DF, Youle RJ. 2009 Parkin-induced mitophagy in the pathogenesis of Parkinson disease. Autophagy 5: 706-708.

Neumann M, Sampathu DM, Kwong LK, Truax AC, Micsenyi MC, Chou TT, Bruce J, Schuck T, Grossman M, Clark CM, et al. 2006. Ubiquitinated TDP-43 in frontotemporal lobar degeneration and amyotrophic lateral sclerosis. Science 314: 130-133.

Nishi T, Forgac M. 2002. The vacuolar $\left(\mathrm{H}^{+}\right)$-ATPasesnature's most versatile proton pumps. Nat Rev Mol Cell Biol 3: 94-103.

Nixon RA. 2004. Niemann-Pick Type C disease and Alzheimer's disease: The APP-endosome connection fattens up. Am J Pathol 164: 757-761.

Nixon RA. 2007. Autophagy, amyloidogenesis and Alzheimer disease. J Cell Sci 120: 4081-4091.

Nixon RA, Cataldo AM. 2006. Lysosomal system pathways: Genes to neurodegeneration in Alzheimer's disease. Alzheimer's Dis 9: 277-289.

Nixon RA, Yang DS. 2011. Autophagy failure in Alzheimer's disease-Locating the primary defect. Neurobiol Dis 43: $38-45$.

Nixon RA, Wegiel J, Kumar A, Yu WH, Peterhoff C, Cataldo A, Cuervo AM. 2005. Extensive involvement of autophagy in Alzheimer disease: An immuno-electron microscopy study. J Neuropathol Exp Neurol 64: 113-122.

Nixon RA, Yang DS, Lee JH. 2008. Neurodegenerative lysosomal disorders: A continuum from development to late age. Autophagy 4: 590-599.

Nukina N, Ihara Y. 1986. One of the antigenic determinants of paired helical filaments is related to tau protein. J Biochem 99: 1541-1544.

Nukina N, Kosik KS, Selkoe DJ. 1987. Recognition of Alzheimer paired helical filaments by monoclonal neurofilament antibodies is due to crossreaction with tau protein Proc Natl Acad Sci 84: 3415-3419.

Ohmi K, Kudo LC, Ryazantsev S, Zhao HZ, Karsten SL, Neufeld EF. 2009. Sanfilippo syndrome type B, a lysosomal storage disease, is also a tauopathy. Proc Natl Acad Sci 106: 8332-8337.

Ohsumi Y. 2001. Molecular dissection of autophagy: Two ubiquitin-like systems. Nat Rev Mol Cell Biol 2: 211-216.

Overly CC, Hollenbeck PJ. 1996. Dynamic organization of endocytic pathways in axons of cultured sympathetic neurons. J Neurosci 16: 6056-6064.

Paine S, Bedford L, Thorpe JR, Mayer RJ, Cavey JR, Bajaj N, Sheppard PW, Lowe J, Layfield R. 2009. Immunoreactivity to Lys63-linked polyubiquitin is a feature of neurodegeneration. Neurosci Lett 460: 205-208.

Peralvarez-Marin A, Barth A, Graslund A. 2008. Timeresolved infrared spectroscopy of $\mathrm{pH}$-induced aggregation of the Alzheimer A $\beta_{1-28}$ peptide. J Mol Biol 379: 589-596.

Petrucelli L, Dickson D, Kehoe K, Taylor J, Snyder H, Grover A, De Lucia M, McGowan E, Lewis J, Prihar G, et al. 2004. CHIP and Hsp70 regulate tau ubiquitination, degradation and aggregation. Hum Mol Genet 13: $703-$ 714.

Pickford F, Masliah E, Britschgi M, Lucin K, Narasimhan R, Jaeger PA, Small S, Spencer B, Rockenstein E, Levine B, et al. 2008. The autophagy-related protein beclin 1 shows reduced expression in early Alzheimer disease and regulates amyloid $\beta$ accumulation in mice. J Clin Invest 118: $2190-2199$.

Pike JW, Donaldson CA, Marion SL, Haussler MR. 1982. Development of hybridomas secreting monoclonal antibodies to the chicken intestinal $1 \alpha, 25$-dihydroxyvitamin D3 receptor. Proc Natl Acad Sci 79: 7719-7723.

Pillay CS, Elliott E, Dennison C. 2002. Endolysosomal proteolysis and its regulation. Biochem J 363: 417-429.

Piper RC, Luzio JP. 2001. Late endosomes: Sorting and partitioning in multivesicular bodies. Traffic 2: 612-621.

Poteryaev D, Datta S, Ackema K, Zerial M, Spang A. 2010. Identification of the switch in early-to-late endosome transition. Cell 141: 497-508.

Rovelet-Lecrux A, Hannequin D, Raux G, Le Meur N, Laquerriere A, Vital A, Dumanchin C, Feuillette S, Brice A, Vercelletto M, et al. 2006. APP locus duplication causes autosomal dominant early-onset Alzheimer disease with cerebral amyloid angiopathy. Nat Genet 38: 24-26.

Rowland AM, Richmond JE, Olsen JG, Hall DH, Bamber BA. 2006. Presynaptic terminals independently regulate synaptic clustering and autophagy of GABAA receptors in Caenorhabditis elegans. J Neurosci 26: 1711-1720.

Roy AK, Oh T, Rivera O, Mubiru J, Song CS, Chatterjee B. 2002. Impacts of transcriptional regulation on aging and senescence. Ageing Res Rev 1: 367-380.

Rusten TE, Simonsen A. 2008. ESCRT functions in autophagy and associated disease. Cell Cycle 7: 1166-1172.

Ryazantsev S, Yu WH, Zhao HZ, Neufeld EF, Ohmi K. 2007. Lysosomal accumulation of SCMAS (subunit c of mitochondrial ATP synthase) in neurons of the mouse model of mucopolysaccharidosis III B. Mol Genet Metab 90: 393-401.

Sahu R, Kaushik S, Clement CC, Cannizzo ES, Scharf B, Follenzi A, Potolicchio I, Nieves E, Cuervo AM, Santambrogio L. 2011. Microautophagy of cytosolic proteins by late endosomes. Dev Cell 20: 131-139.

* Saido T, Leissring MA. 2011. Proteolytic degradation of amyloid $\beta$-protein. Cold Spring Harb Perspect doi: 10.1101.cshperspect.a006379.

Schmidt ML, DiDario AG, Lee VM, Trojanowski JQ. 1994. An extensive network of PHF tau-rich dystrophic neurites permeates neocortex and nearly all neuritic and diffuse amyloid plaques in Alzheimer disease. FEBS Lett 344: 69-73.

Seshadri S, Fitzpatrick AL, Ikram MA, DeStefano AL, Gudnason V, Boada M, Bis JC, Smith AV, Carassquillo MM, Lambert JC, et al. 2010. Genome-wide analysis of genetic loci associated with Alzheimer disease. JAMA 303: $1832-1840$.

Setsuie R, Wada K. 2007. The functions of UCH-L1 and its relation to neurodegenerative diseases. Neurochem Int 51: $105-111$.

Settembre C, Di Malta C, Polito VA, Garcia Arencibia M, Vetrini F, Erdin S, Erdin SU, Huynh T, Medina D, Colella $\mathrm{P}$, et al. 2011. TFEB links autophagy to lysosomal biogenesis. Science 332: 1429-1433.

Simonsen A, Tooze SA. 2009. Coordination of membrane events during autophagy by multiple class III PI3-kinase complexes. J Cell Biol 186: 773-782. 
Y. Ihara et al.

Sleegers K, Brouwers N, Gijselinck I, Theuns J, Goossens D, Wauters J, Del-Favero J, Cruts M, van Duijn CM, Van Broeckhoven C. 2006. APP duplication is sufficient to cause early onset Alzheimer's dementia with cerebral amyloid angiopathy. Brain 129: 2977-2983.

Smemo S, Nowotny P, Hinrichs AL, Kauwe JS, Cherny S, Erickson K, Myers AJ, Kaleem M, Marlowe L, Gibson AM, et al. 2006. Ubiquilin 1 polymorphisms are not associated with late-onset Alzheimer's disease. Ann Neurol 59: $21-26$.

Sohal RS, Mockett RJ, Orr WC. 2002. Mechanisms of aging: An appraisal of the oxidative stress hypothesis. Free Radic Biol Med 33: 575-586.

Soto C. 2003. Unfolding the role of protein misfolding in neurodegenerative diseases. Nat Rev Neurosci 4: 49-60.

Spillantini MG, Schmidt ML, Lee VM, Trojanowski JQ, Jakes R, Goedert M. 1997. Alpha-synuclein in Lewy bodies. Nature 388: 839-840.

Spilman P, Podlutskaya N, Hart MJ, Debnath J, Gorostiza O, Bredesen D, Richardson A, Strong R, Galvan V. 2010. Inhibition of mTOR by rapamycin abolishes cognitive deficits and reduces amyloid- $\beta$ levels in a mouse model of Alzheimer's disease. PLoS One 5: e9979.

Sun B, Zhou Y, Halabisky B, Lo I, Cho SH, Mueller-Steiner S, Devidze N, Wang X, Grubb A, Gan L. 2008. Cystatin Ccathepsin $B$ axis regulates amyloid $\beta$ levels and associated neuronal deficits in an animal model of Alzheimer's disease. Neuron 60: 247-257.

Syntichaki P, Tavernarakis N. 2003. The biochemistry of neuronal necrosis: Rogue biology? Nat Rev Neurosci 4: $672-684$.

Takahashi RH, Milner TA, Li F, Nam EE, Edgar MA, Yamaguchi H, Beal MF, Xu H, Greengard P, Gouras GK. 2002. Intraneuronal Alzheimer a $\beta 42$ accumulates in multivesicular bodies and is associated with synaptic pathology. Am J Pathol 161: 1869-1879.

Tank EM, True HL.2009. Disease-associated mutant ubiquitin causes proteasomal impairment and enhances the toxicity of protein aggregates. PLoS Genet 5: e1000382.

Terman A. 2001. Garbage catastrophe theory of aging: Imperfect removal of oxidative damage? Redox Rep 6: $15-26$.

Terry RD, Masliah E, Salmon DP, Butters N, DeTeresa R, Hill R, Hansen LA, Katzman R. 1991. Physical basis of cognitive alterations in Alzheimer's disease: Synapse loss is the major correlate of cognitive impairment. Ann Neurol 30: 572-580.

Tian Y, Bustos V, Flajolet M, Greengard P. 2011. A smallmolecule enhancer of autophagy decreases levels of $A\{\beta\}$ and APP-CTF via Atg5-dependent autophagy pathway. FASEB J 25: 1934-1942.

Tresse E, Salomons FA, Vesa J, Bott LC, Kimonis V, Yao TP, Dantuma NP, Taylor JP. 2010. VCP/p97 is essential for maturation of ubiquitin-containing autophagosomes and this function is impaired by mutations that cause IBMPFD. Autophagy 6: 217-227.

Troen BR. 2003. The biology of aging. Mt Sinai J Med 70: $3-22$.

Tseng BP, Green KN, Chan JL, Blurton-Jones M, LaFerla FM. 2008. A $\beta$ inhibits the proteasome and enhances amyloid and tau accumulation. Neurobiol Aging 29: 1607-1618.

van Leeuwen FW, de Kleijn DP, van den Hurk HH, Neubauer A, Sonnemans MA, et al. 1998. Frameshift mutants of $\beta$ amyloid precursor protein and ubiquitin- $\mathrm{B}$ in $\mathrm{Alz}$ heimer's and Down patients. Science 279: 242-247.

Vito P, Lacana E, D'Adamio L. 1996. Interfering with apoptosis: $\mathrm{Ca}^{2+}$-binding protein ALG-2 and Alzheimer's disease gene ALG-3. Science 271: 521-525.

Vito P, Pellegrini L, Guiet C, D’Adamio L. 1999. Cloning of AIP1, a novel protein that associates with the apoptosis-linked gene ALG-2 in a $\mathrm{Ca}^{2+}$-dependent reaction. J Biol Chem 274: 1533-1540.

Walsh DM, Selkoe DJ. 2004. Deciphering the molecular basis of memory failure in Alzheimer's disease. Neuron 44: $181-189$.

Wang Y, Martinez-Vicente M, Kruger U, Kaushik S, Wong E, Mandelkow EM, Cuervo AM, Mandelkow E. 2009. Tau fragmentation, aggregation and clearance: The dual role of lysosomal processing. Hum Mol Genet 18: 4153-4170.

Weidberg H, Shvets E, Elazar Z. 2011. Biogenesis and cargo selectivity of autophagosomes. Annu Rev Biochem 80: 125-156.

Wischik CM, Crowther RA, Stewart M, Roth M. 1985. Subunit structure of paired helical filaments in Alzheimer's disease. J Cell Biol 100: 1905-1912.

Wong E, Cuervo AM. 2010. Autophagy gone awry in neurodegenerative diseases. Nat Neurosci 13: 805-811.

Wood JG, Mirra SS, Pollock NJ, Binder LI. 1986. Neurofibrillary tangles of Alzheimer disease share antigenic determinants with the axonal microtubule-associated protein tau (tau). Proc Natl Acad Sci 83: 4040-4043.

Xu P, Peng J. 2006. Dissecting the ubiquitin pathway by mass spectometry. Biochim Biophys Acta 1764: 1940-1947.

Xu P, Peng J. 2008. Characterization of polyubiquitin chain structure by middle-down mass spectrometry. Anal Chem 80: 3438-3444.

Yang AJ, Chandswangbhuvana D, Margol L, Glabe CG. 1998. Loss of endosomal/lysosomal membrane impermeability is an early event in amyloid A $\beta 1-42$ pathogenesis. J Neurosci Res 52: 691-698.

Yang DS, Kumar A, Stavrides P, Peterson J, Peterhoff CM, Pawlik M, Levy E, Cataldo AM, Nixon RA. 2008. Neuronal apoptosis and autophagy cross talk in aging PS/APP mice, a model of Alzheimer's disease. Am J Pathol 173: 665-681.

Yang DS, Stavrides P, Mohan PS, Kaushik S, Kumar A, Ohno M, Schmidt SD, Wesson D, Bandyopadhyay U, Jiang Y, et al. 2011. Reversal of autophagy dysfunction in the TgCRND8 mouse model of Alzheimer's disease ameliorates amyloid pathologies and memory deficits. Brain 134: $258-277$.

Yoshii SR, Kishi C, Ishihara N, Mizushima N. 2011. Parkin mediates proteasome-dependent protein degradation and rupture of the outer mitochondrial membrane. $J$ Biol Chem 286: 19630-19640.

Youle RJ, Narendra DP. 2011. Mechanisms of mitophagy. Nat Rev Mol Cell Biol 12: 9-14.

Yu WH, Cuervo AM, Kumar A, Peterhoff CM, Schmidt SD, Lee J-H, Mohan PS, Mercken M, Farmery MR, Tjernberg 
LO, et al. 2005. Macroautophagy-A novel $\beta$-amyloid peptide-generating pathway activated in Alzheimer's disease. J Cell Biol 171: 87-98.

Zhang M. 2008. Endocytic mechanisms and drug discovery in neurodegenerative diseases. Front Biosci 13: 6086-6105.

Zhang JY, Liu SJ, Li HL, Wang JZ. 2005. Microtubuleassociated protein tau is a substrate of ATP $/ \mathrm{Mg}^{2+}$ dependent proteasome protease system. J Neural Transm 112: $547-555$.

Zhao J, Brault JJ, Schild A, Cao P, Sandri M, Schiaffino S, Lecker SH, Goldberg AL. 2007. FoxO3 coordinately activates protein degradation by the autophagic/lysosomal and proteasomal pathways in atrophying muscle cells. Cell Metab 6: 472-483. 


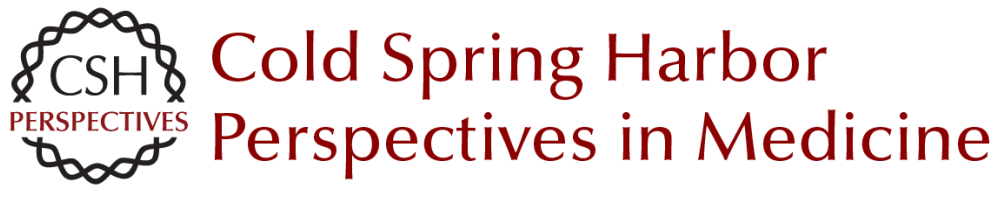

\section{The Ubiquitin-Proteasome System and the Autophagic-Lysosomal System in Alzheimer Disease}

Yasuo Ihara, Maho Morishima-Kawashima and Ralph Nixon

Cold Spring Harb Perspect Med 2012; doi: 10.1101/cshperspect.a006361 originally published online April 4, 2012

Subject Collection The Biology of Alzheimer Disease

Animal Models of Alzheimer Disease

Frank M. LaFerla and Kim N. Green

Neurovascular Dysfunction and Faulty Amyloid $\beta$

-Peptide Clearance in Alzheimer Disease

Abhay P. Sagare, Robert D. Bell and Berislav V. Zlokovic

Treatment Strategies Targeting Amyloid $\beta$-Protein Dale Schenk, Guriqbal S. Basi and Menelas N. Pangalos

The Ubiquitin-Proteasome System and the Autophagic-Lysosomal System in Alzheimer Disease

Yasuo Ihara, Maho Morishima-Kawashima and Ralph Nixon

Neurotoxicity of Amyloid $\beta$-Protein: Synaptic and Network Dysfunction Lennart Mucke and Dennis J. Selkoe

Proteolytic Degradation of Amyloid $\beta$-Protein Takaomi Saido and Malcolm A. Leissring

Brain Imaging in Alzheimer Disease Keith A. Johnson, Nick C. Fox, Reisa A. Sperling, et al.

Symptomatic and Nonamyloid/Tau Based Pharmacologic Treatment for Alzheimer Disease Paul S. Aisen, Jeffrey Cummings and Lon S. Schneider
Alzheimer Disease in 2020

David M. Holtzman, Eckhard Mandelkow and Dennis J. Selkoe

The Genetics of Alzheimer Disease Rudolph E. Tanzi

Fluid Biomarkers in Alzheimer Disease

Kaj Blennow, Henrik Zetterberg and Anne M. Fagan

Epidemiology of Alzheimer Disease

Richard Mayeux and Yaakov Stern

Biochemistry and Cell Biology of Tau Protein in Neurofibrillary Degeneration

Eva-Maria Mandelkow and Eckhard Mandelkow

Biochemistry of Amyloid $\beta$-Protein and Amyloid

Deposits in Alzheimer Disease

Colin L. Masters and Dennis J. Selkoe

The Neuropsychological Profile of Alzheimer

Disease

Sandra Weintraub, Alissa H. Wicklund and David P. Salmon

Apolipoprotein E and Apolipoprotein E Receptors: Normal Biology and Roles in Alzheimer Disease David M. Holtzman, Joachim Herz and Guojun Bu

For additional articles in this collection, see http://perspectivesinmedicine.cshlp.org/cgi/collection/ 